\title{
LA-8246-M
}

Manual

\section{The Los Alamos Scientific Laboratory X-Ray Survey Manual}


LA-8246-M

Manual

Issued: February 1980

\section{The Los Alamos Scientific Laboratory $X$-Ray Survey Manual}

Richard H. Olsher
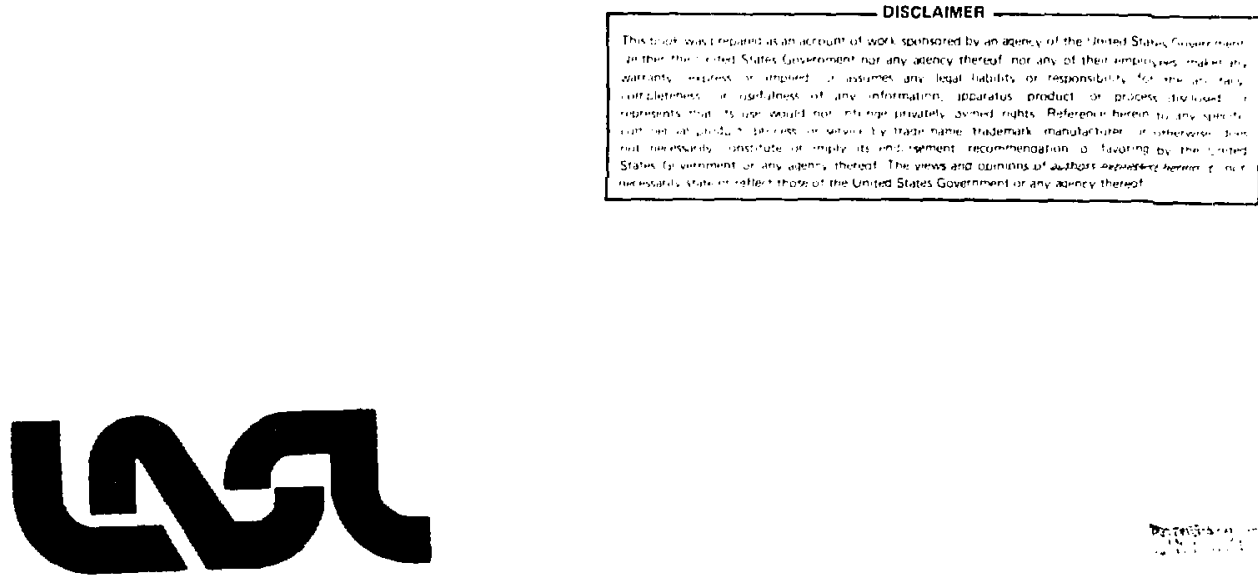
CONTENTS

THE LOS ALAMOS SCIENTIFIC LABORATORY X-RAY SURVEY MANUAL

ABSTRACT. . . . . . . . . . . . . . . . . . . . . . . 1

I. X-RAY DIFFRACTION \& FLUORESCENCE ANALYSIS SYSTEMS . . . 3

II. INDUSTRIAL CABINET X-RAY SYSTEMS. . . . . . . . . 12

III. INDUSTRIAL NONCABINET X-RAY SYSTEMS . . . . . . . 23

IV. ELECTRON MICROSCOPES. . . . . . . . . . . . . . 37

APPENDIX A. ENERGY DEPENDENCE CORRECTION FACTORS . . . . . . 44

APPENDIX B. LASL X-RAY DEVICE CONTROL PROGRAM. . . . . . . . 49 
THE LOS ALAMOS SCIENTIFIC LABORATORY X-RAY SURVEY MANUAL

by

Richard H. Olsher

\begin{abstract}
A manual has been developed by the Health Physics Group to establish procedures for routine testing of industrial and analytical $x$-ray equipment for compliance with applicable LASL administrative requirements and technical bulletins. Radiation protection survey procedures were developed for the following types of equipment: $x$-ray diffraction and fluorescence analysis systems, industrial cabinet $x$-rav systems, industrial noncabinet $\mathrm{x}$-ray systems, and electron microscopes.
\end{abstract}




\section{INTRODUCTION}

This manual was developed by the Health Physics Group ( $\mathrm{H}-1$ ) to establish procedures for routine testing of $x$-ray generating devices for compliance with applicable LASL administrative requirements and technical bulletins.

Test procedures are provided for the following types of equipment:

- $x$-ray diffraction and fluorescence analysis systems

- industrial cabinet $\mathrm{x}$-ray systems

o Industrial noncabinet $\mathrm{x}$-ray systems

- electron microscopes

Energy dependence correction factors for several $x$-ray survey meters are provided in Appendix A. The LASL x-ray device control program is outlined in Appendix B (Administrative Requirements 5-3 and Technical Bulletins 530, 531 , and 532).

Testing will be conducted by those $\mathrm{H}-\mathrm{l}$ Health Physics technicians that have been certified by Group $\mathrm{H}-1$ as $\mathrm{x}$-ray surveyors. 


\section{PART I}

This survey procedure is applicable to $x$-ray diffraction and $x$-ray fluorescence spectrometry equipment. It is designed to determine compliance of such equipment with the applicable health and safety requirements in LASi's Health, Safety and Environment Manual. See Administrative Requirements $5-3$ and Technical Bulletin 530 (Appendix B) for applicable requirements.

Because beams of small cross section may be encountered during exposure rate measurements around these machines, an ionization chamber with a cross-sectional area no larger than $10 \mathrm{~cm}^{2}$ should be used (e.g., the Victoreen Model 440RF/C). The use of a thin-window Geiger counter is recommended, however, for detecting or localizating radiation beams. After the beam is detected with a Geiger counter, the ionization chamber should be used to obtain a quantitative measurement since readings obtained with the Geiger counter in the sofit $x$-ray range are unreliable. 
X-RAY DIFFRACTION \& FLUORESCENCE ANALYSIS SYSTEMS

RADIATION PROTECTION SURVEY PROCEDURE

(For use with LASL Form XS-101)

1. Surveyor Information. Complete all items.

2. Location \& Machine Data. Complete all items.

3. Radiation Protection Program

a. Item 1. Review the radiation dosimetry records of the past year for all authorized operators. Note any unusual trends in the Comments section.

b. Items 2-5. Self-explanatory.

c. Item 6. See the machine custodian and check his training documentation for each authorized operator. Note any discrepancies in the Comments section.

d. Item 7. Self-explanatory.

4. Radiation Safety Checklist

Evaluate the $x$-ray system against the applicable requirements of the radiation safety checklist. Record any deficiencies in items 8-12 using the letter designations of the requirements not met. Explanations or clarifications should be made in the Comments section.

Requirement

(a)

(b)

(c)

(d)

\section{Guidance}

Check the viewing apertures on all powder diffraction cameras to determine if they provide a sufficient beam stop. Have each camera mounted in the tube port without a sample or film. With the $x$-ray system energized to normal $m A$ and $k V p$, check for transmission through the aperture with the victoreen $440 \mathrm{RF} / \mathrm{C}$ survey meter. Exposure rates in excess of $0.5 \mathrm{mR} / \mathrm{hr}$ would indicate an inadequate beam stop; unless, of course, the reading is due to tube housing leakage.

Self-explanatory.

This requirement may be satisfied by the warning light described in (b) above, if it is clearly visible from the $x$-ray switch and is labeled "X-RAYS ON" or other similar words.

Self-explanatory. 
(e)

There is usually a microswitch located on the tube housing for each port that must be depressed by the camera coupling in order to open the shutter. Make sure that none of these microswitches are defeated in order to accommodate noncompatible cameras. All cameras used in a given port must activate the shutter interlock. Also, verify that it is not possible to open any shutter without depressing the appropriate microswitch.

A 1ight or a mechanical indicator are both acceptable shutter status indicators. Open and close each shutter several times while checking for proper cycling of the status indicator. Also, take note of any shutter that tends to stick open while being closed.

It should not be possible to open a shutter on an unused port without first having to take some positive action such as activating an interlock or removing a restraining bracket.

There are commercially available radiation shields that totally enclose the $x$-ray path of a vertical or horizontal diffractometer, thus converting it from an open to an enclosed beam system. Determine if there are any operational requirements (see TB 530) which would make a fully enclosed beam impractical. Even if this is the case, it should still be possible to provide some sort of protective guard which would reduce the probability of an accidental finger or hand insertion into the primary beam.

Self-explanatory.

Energize the $x$-ray tube and open the sample chamber. With a survey meter, verify that no radiation is present inside the chamber.

5. Radiation Measurements

a. Items 13-14. Have the $\mathrm{x}$-ray system energized to the highest values of $\mathrm{mA}$ and $\mathrm{kVp}$ normally used. Record these readings.

b. Items 15-17. Self-explanatory.

c. Items 18-19. Determine the $x$-ray tube target and filter materials. Based on this information, select an effective energy from the Table below.

Target Element
Chromium (Cr)
Iron (Fe)
Cobalt ( $\mathrm{Co})$
Nickel (Ni)
Copper ( Cu)
Molybdenum (Mo)
Silver (Ag)

\begin{tabular}{lc}
\multicolumn{1}{c}{ Filter Element } & Effective Energy (keV) \\
Vanadium (V) & 5.4 \\
Manganese (Mn) & 6.4 \\
Iron (Fe) & 6.9 \\
Coba1t (Co) & 7.5 \\
Nickel (Ni) & 8.1 \\
Zirconium (Zr) & 17 \\
Protactinium (Pa) & 22
\end{tabular}


If the target material is unknown or is Tungsten (W), estimate the effective energy of the beam as one third of the selected $\mathrm{kVp}$ :

$$
\mathrm{keV}=\frac{\mathrm{kVp}}{3},
$$

Determine the energy correction factor (t) for) for the meter and window cover based on this effective energy.

d. Item 20. Close all beam shutters and maintain the $\mathrm{kVp}$ and $\mathrm{mA}$ values recorded in items 13 and 14 . With a thin window GM counter, scan al1 surfaces of the $x$-ray tube housing. Identify the highest reading area and quantitate the exposure rate with the Victoreen $440 \mathrm{RF} / \mathrm{C}$. Record the maximum measured exposure rate and correct it by multiplying with the range correction factor and dividing by the energy correction factor. The corrected exposure rate must not be greater than $0.5 \mathrm{mR} / \mathrm{hr}$ or else additional shielding would have to be added to the tube housing to reduce the leakage to this level.

e. Items 21-22. Prepare the $\mathrm{x}$-ray system for secondary radiation measurements as follows:

Open Beam: Have the operator load samples into each diffractometer. If power diffraction cameras are used at any other port, have the operator position empty cameras at these ports. Have the operator position scatter shields normally used with the system.

Enclosed Beams: Have the operator load a typical sample in place.

Open beam shutters at used ports and energize the $x$-ray tube to the values recorded In items 13 and 14 . Using a thin window GM counter, scan a:1 surfaces of the enclosed beam system. For open beams, scan at the edge of the tube housing table and the external surface of any scatter field. Select several locations with significant readings for quantitative evaluation. Draw a schematic of the $x$-ray system in Item 21 showing tnese selected locations. Number each selected location.

Place a Victoreen $440 \mathrm{RF} / \mathrm{C}$ at each of these locations and measure the exposure rate. Record the results and the appropriate range correction factors in Item 22. Correct the recorded exposure rates by multiplying with the range correction factor and dividing by the energy correction factor.

6. LASL Compliance

Item 23. The new survey due date you should select depends on the type of deficiencles found during the present survey: 


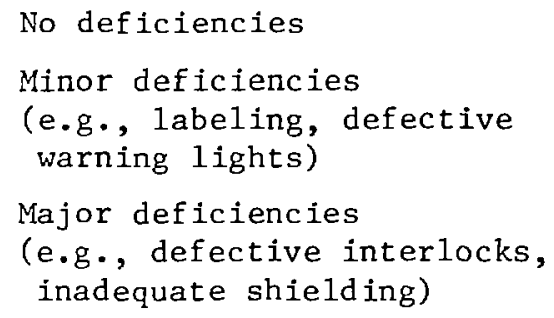

1 year from present survey

3 months from present survey

DO NOT update labe1

For systems with minor deficiencies, plan to resurvey within three months but only after the machine custodian informs you that all corrective actions have been completed. During the resurvey only check to see that all deficiencies have been corrected and if so, extend the new survey date by another nine months. Send a memo describing the 3 -month resurvey results to the machine custodian with copies to the responsible $\mathrm{H}-1 \mathrm{HP}$ and the $\mathrm{X}$-ray Control office.

If in your judgement, however, major hazards need correction, you should effectively pull the plug by not updating the label. Discuss this action with the machine custodian and request him to call you for a resurvey when all corrections have been accomplished.

7. Comments

Any necessary explanations or clarifications should be recorded here.

8. Recommendations

Recommendations may be made by the surveyor, the Health Physics Section Leader, or the X-ray Control office. Recommendations should be initialed by the person making them. If there are none, so state.

9. $\mathrm{H}-1$ Review

The survey report will be reviewed by the responsible Health Physics Section Leader and the $X$-ray Control office. The reviewers should sign the form where indicated. 


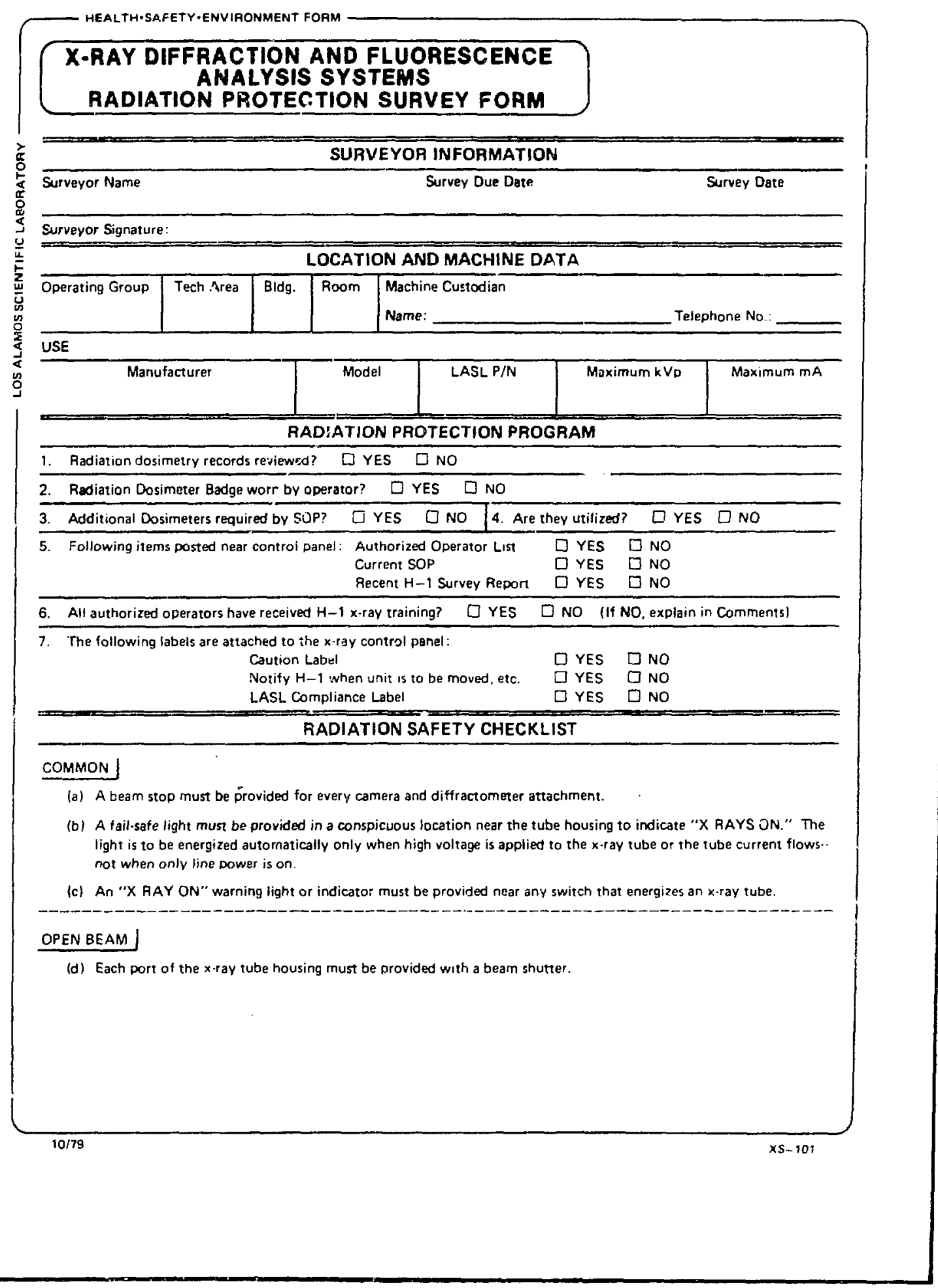


(e) Whenever the accessory setup is not permanent li.e., subject to change frequently or periodically as is the case with powder diffraction camerast. the shutter must be interlocked with every accessory apparatus coupling or collimator used, such that the port will only be open when the collımator or coupling is in place.

(f) Ail shutters must be provided with a conspicuous "Shurter Open" indicator of fail-safe design.

(g) Beam shusters at unused ports should be secured to prevent casual opening.

(h) A guard or interlock which prevents entry of any part of the body into the primary beam shoutd be provided -. - - - - ENCLOSED BEAM

(1) The $x$.ray tube, sample. detector, and anaiyzıng crystal lif used) must be enclosed in a chamber or coupled chambers that canno: be entered by any part of the body during normal operation.

(j) The sample chamber door must be interlocked with the $x \cdot$ ray tube high voltage supply or a shutter in the primary beam so that no $x$ ray beam can cnter the sample chamber while it is open.

\section{DEFICIENCIES}

8 Fully Enclosed Beam System

\section{OEFICIENCIES}

9 Port $=1$ Open Eeim

$\square$ Enclosed Beam

\section{DEFICIENCIES}

10 Port $\approx 2$ ¿ Open Seam

T. Enclosed Beam

\section{DEFICIENCIES}

11. Port $=3$ :- Oper. Beam

if Enclosed Beam

\section{DEFICIENCIES}

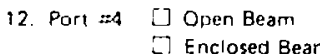

\begin{tabular}{|c|c|c|c|}
\hline \multicolumn{4}{|c|}{ RADIATION MEASUREMENTS } \\
\hline Selected kVp & & \multicolumn{2}{|c|}{ 14. Selected $\mathrm{mA}$} \\
\hline \multicolumn{4}{|c|}{ INSTRUMENTATION } \\
\hline MFG/Aradel & 16. LA.Z!. P/N & & 17. Window Cover -. ON, OFF, or N/A \\
\hline Effect ve Energy = & 19. Ener & ection Factor = & $ـ_{(E C F)}$ \\
\hline
\end{tabular}

20 Maxim im Tube Housing leakage (Open Beam System Only)

- $m R / h \times$ ACF $1,1 \div$ ECF $1,1=\ldots$ mA/h (must be less than $0.5 \mathrm{raR} / \mathrm{h}$ ) 
21. Schematic of System showing secondary radiation measurement locations:

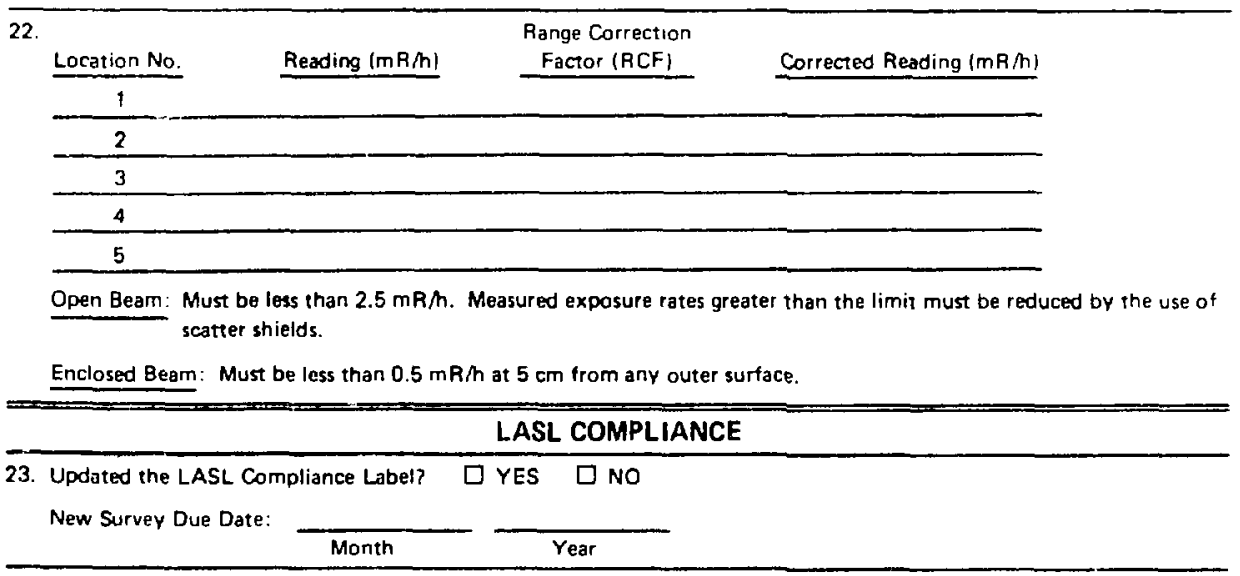




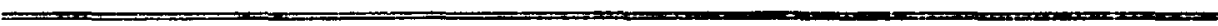

ITEM NO.

COMMENTS

SECTION LEADER:

$X$.RAY CONTROL OFFICE

Distribution: Original -Operating Group Leader

Xc: Machine Custodian (1)

Health Physics Section (1)

$X \cdot$ Ray Control Office (1) 
This survey procedure is applicable to industrial cabinet $x$-ray systems. It is designed to determine compliance of such systems with the applicable health and safety requirements in LASi.'s Health, Safety and Environment Manual. See Administrative Requirements 5-3 and Technical Bulletin 531 (Appendix B) for applicable requirements.

Because the Federal Performance Standard for cablnet $x$-ray systems specifies that exposure rate measurements be averaged over an area not larger than $10 \mathrm{~cm}_{2}^{2}$, an ionization chamber of cross-sectional area not larger than $10 \mathrm{~cm}^{2}$ should be used (e.g., Victoreen Model 440RF/C). 


\section{INDUSTRIAL CABINET X-RAY SYSTEMS \\ RADIATION PROTECTION SURVEY PROCFDURE}

(For use with LASL Form XS-102)

1. Surveyor Information. Complete all items.

2. Lcration and Machine Data

a. Complete all items.

b. Item 1. Federal regulations require that cabinet $x$-ray systems manufactured on or after April 10, 1975, be certified by the manufacturer as complying with the Federal performance standard 21CFR 1020.40. The certification by the manufacturer is in the form of a label or a tag which is affixed to the system. Look for such a label somewhere on the control console. If you find it, answer "yes" to item 1 .

Keep in mind that for certified systems, the manufacturer is obligated to correct ary noncompliances free of charge (through repair, replacement, or refund of cost) throughout the useful life of the equipment--providing that the user followed the prescribed maintenance schedule.

c. Item 2. Is the system designed to allow individuals to walk into the interior of the cabinet? If so, answer "yes."

\section{Radiation Protection Program}

a. Item 3. Review the radiation dosimetry records of the past year for all authorized operators. Note any unusual trends in the Comments section.

b. Item 4-5. Self-explanatory.

c. Item 6. See the machine custodian and check his training documentation for each authorized operator. Note any discrepancies in the Comments section.

d. Item 7. Self-explanatory.

4. Ports and/or Apertures

a. Item 8. Determine if any part of the body (e.g., arm or leg) can be inserted through a port into the primary beam. The port should provide sufficient distance from the primary beam so that reaching the primary beam is not possible. If the response is "yes" explain in the Comments section giving the specific port(s) and the circumstances involved.

b. Item 9. Determine if any part of the body can be inserted through any aperture. Apertures should be baffled so that reaching the inside of the 
cabinet is not possible. If the response is "yes" explain in the Comments section giving the specific aperture(s) and the circumstances involved.

\section{Controls and Indfcatozs}

a. Item 10. Have the operator turn on power to the system. Have him set the $x$-ray control to the lowest selectable values of $k v_{p}$ and $m A$. Is there an "x-ray on" control provided which can energize and de-energize the $x$-ray tube? If so, respond "yes."

B. Item 11-12. Momentarily energize the $x$-ray tube. Is a conspicuous warning light or indicator labeled with the words "X RAYS ON," or similar words located near any switch which energizes an x-ray tube? By consplcuous is meant a jight or indicator of sufficient size and intensity and/or of a rotating or flashing type design. Walk over to every door and port. Is a waming light or indicator, as described above, clearly visible from each cabinet door and port? One light may satisfy the requirements of 1 tems 11 and 12 if it is close to both the door or port and the control panel.

Note that these lights or indicators must only be activated when $x$-rays are produced. That is, when high voltage is applied to the $x$-ray tube or when tube current flows. They should not be actlvated when only the line power switch is turned on.

c. Item 13. Self-explanatory.

6. Safety Interlocks

a. Item 14. Open each door to see if two interlocks or a physical disconnect and an interlock are visible around the door seal.

B. Item 15. X-ray production must be prevented when any door or access pane1 ts open. Where possible, all doors and access panels should be tested to assure prevention of $x$ radiation. CAUTION: Not all access panels should be opened. Do not attempt to open any panel of a compartment containing an Image intensifier (systems with fluoroscopic capability) because room light may severely damage the intensifier. Also, if access panels are sealed, do not break the seals in an attempt to open the panels.

Energlze the $x$-ray tube and slightly open each door and access panel. Note whether $x$-ray production is terminated by observing the $\mathrm{mA}$ meter or warning light at the control panel. This is not possible with pulsed systems or machines with short exposure times. In this case slightly open each door and access panel separately and then attempt to initiate $x$-ray production.

c. Item 16. Energize the $x-$ ray tube. Open the door slightly and then close it. Does $x$-ray production resume Immediately or does the " $x$ ray on" control have to be used to resume operation? Repeat for any other doors. For cabinets designed to admit humans (walk-in type), use of the " $x$ ray on" control must be necessary to produce $x$ rays after opening and closing the door. 
Note: Skip section 7 if system is not designed to admit humans.

7. Systems Designed to Adnit Humans

a. Items 17-18. Determine if a control is located within the cabinet for preventing and terminating $x$-ray production (panic or scram switch). Activate this control, proceed to the outside of the cabinet, close the door, and determine if the control can be overriden, reset, or bypassed from the outside of the cabinet. Try to produce $x$ rays. Once the panic switch is activated, it should require resetting inside the cabinet before $x$ rays can be produced.

b. Item 19. There should be no way of initiating $x$-ray production from inside the cabinet.

c. Items 20-21. Determine if audible and visible signals are contained within the cabinet which are activated for at least 10 seconds immediately prior to the initiation of x-ray production after closing any docr designed to admit humans. Close the door and wait about half a minute before starting an exposure with the "X RAY ON" control. This is to ensure that closing of the door does not activate the signals. The visibie warning signal should remain activated during $x$-ray production.

NOIE: IL may not always be possible to tell from outside the cabinet whether or not the warning signals have been actirated and whether the visible warning signal remains activated during $x$-ray production. Do not remain within the cabinet for this test.

d. Item 21. These signs should preferably be of the type that illuminate when the main power switch is in the "on" position.

\section{Leakage Radiation}

a. Items 23-24. Have the operator set the $x$-ray control to the highest selectable $\mathrm{kVp}$ and to the highest $\mathrm{mA}$ allowed by the tube rating chart for the $k V p$ selected.

b. Item 25. If the $x$-ray tube orientation is not variable, place a scatter clock in the path of the primary bearn at a position of normal operation. The dimensions of the scatter block should be at least equal to those of the $x$-ray field. For tube potentials in the range of $50-150 \mathrm{kVp}$, the optimum scatter block is about 3 inches of luctte or paper. However, if either lucite or paper are unavailable, other materials with a similar hydrogen content (e.g., wood) may be substituted. If the $x$-ray tube orientation is variable, do not use a scatter block--but maximize the leakage conditions by directing the primary beam at, and locating the tube as closely as possible to the surface being tested, provided that such positioning and orientation will serve a practical purpose in normal usage and is not prohibited by the SOP. Whenever leakage is measured with the primary beam directed at the cabinet surfaces, enter "none" in item 25. 
c. Item 26. Based on the x-ray tube rating chart or on information provided in the operating manual, determine the system's duty cycle for the selected $\mathrm{kVp}$ and $\mathrm{mA}$. Record the duty cycle elther in minutes per hour or in pulses per hour as appropriate. Convert minutes per hour to percent by multiplying by $100 / 60$. For example, $10 \mathrm{~min} / \mathrm{hr} \times 100 / 60=16.67 \%$.

d. Item 27 .

(1) Continuously activated systems (systems capable of exposure times greater than 10 seconds).

Initiate exposure and scan the external surfaces of the cabinet with a thin window GM counter to identify locations of highest radiation leakage. Select locations with any significant readings for quantitative measurements. Draw a schematic of the cabinet and number the locations selected.

(2) Noncontinuous exposure systems (systems with exposure times less than 10 seconds).

Select several locations at the cabinet surface that would appear to have the more significant leakage (e.g., around doors, ports, apertures, or joints). Draw a schematic of the cabinet and number the locations selected.

e. Item 28. Use the Victoreen $440 \mathrm{RF} / \mathrm{C}(0-1 \mathrm{mR} / \mathrm{hr}$ scale) or an equivalent instrument to quantitate the radiation leakage at each of the locations selected. Position the center of the lonization chamber at $5 \mathrm{~cm}$ from the surface of the cabinet at each of the locations selected. The center of the $440 \mathrm{RF} / \mathrm{C}$ chamber is at $5 \mathrm{~cm}$ when the three plastic bumpers on the front of the meter are placed directly against the cabinet surface. Inftlate an exposure of at least 10 seconds at each location. Wait until the meter stabilizes and then record the highest exposure rate obtained at each location.

If measuring at an open port, a piece of masking tape across the opening makes the plane of the cabinet surface more easily determinable.

Correct the readings obtained by multiplying each reading with the duty cycle and dividing by the overall correction factor (CF) as follows:

Corrected Exposure Rate $(m R / h r)=\frac{\text { (Reading) } \times \text { (Duty Cycle in Percent) }}{C F \times 100}$

A11 corrected exposure rates should be no greater than $0.5 \mathrm{mR} / \mathrm{hr}$.

f. Item 29. TLDs will be used for radlation leakage measurements on noncontinuously activated systems. Leakage will be integrated over a reasonable period of time. Arrangements should be made several days in advance of the survey date with the Health Physics Analysis Lab for the required TLDs. Consultation with the X-ray Control office and the Health 
Physics Analysis Iab is recomnended for selection of TLD type and exposure duration.

Place a TLD packet at each selected location. Indicate on the schematic (item 27) the packet number placed at each location. Have the operator integrate a sufficient number of exposure on the TLDs over a period of time: Record the total exposure time in minutes or pulses for each TLD packet. Have the TLJs analyzed and record the readings at item 29 . Correct the TLD realings as follows:

Corrected Fxposure $(m R$ in one hour $)=\frac{\text { (Reading) } x \text { (Duty Cycle) }}{\text { (Total Exposure Time) }}$

where the duty cycle is expressed either in min/hr or pulses/hr and the total exposure time in either minutes or pulses.

\section{?. Isabels}

a. Item 30. Self-explinatory.

b. Item 31. 'The new survey due jate you should select depends on the type of deficiencies found during the present survey:

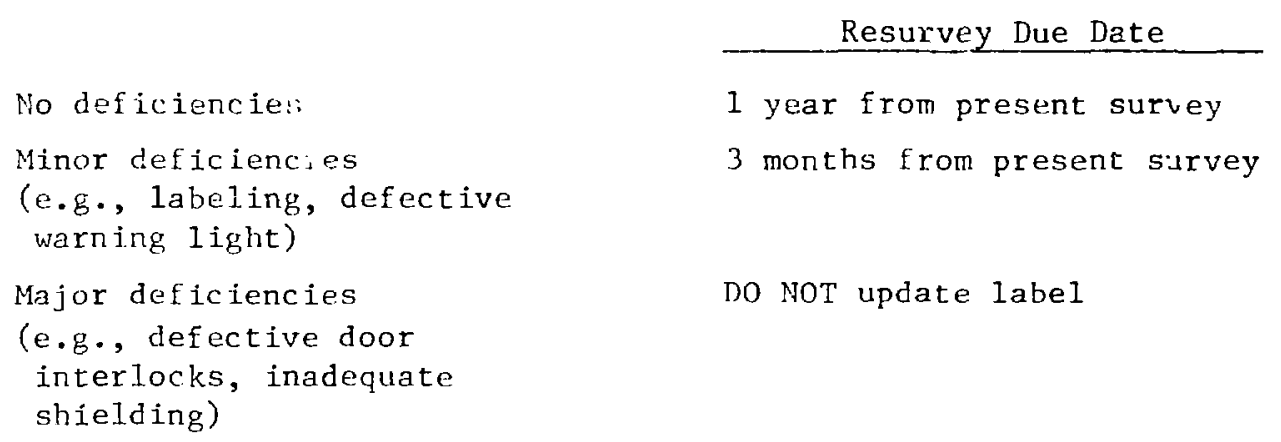

For systems with minor deficiencies, plan to resurvey within three months--but only after the machine custodian informs you that all corrective actions have been completed. During the resurvey only check to see that all deficiencies have been corrected and if so, extend the new survey date by another nine months. Send a memo describing the 3-month resurvey results to the machine custodian with coples to the responsible $\mathrm{H}-1 \mathrm{HP}$ and the $\mathrm{X}$-ray Control office.

If in your judgement, however, major hazasds need correction, you should effectively puli the plug by not updating the label. Discuss this action. with the machine custodian and request him to call you for a resurvey when all corrections have been accomplished. 
10. Instrumentation

a. Items 32-34. Self-explanatory.

B. Items 35-36. Estimate the effective energy of the beam as a third of the selected $\mathrm{kVp}$. Determine the energy correction factor for the meter and window cover based on this effective energy. Divide this factor by the calibration correction factor (see chart on side of instrument) to determine the overall Correction Factor (CF).

11. Comments

Any necessary explanations or clarifications snould be recorded here.

12. Recommendations

Recommendations may be made by the surveyor, the Health Physics Section Leader, or the X-Ray Control office. Recommendations should be initialed by the person making them. If there are none, so state.

13. $\mathrm{R-1}$ Review

The survey report w1ll be reviewed by the responsible Health Physics Section Leader and the $X$-ray Control office. The reviewers should sign the form where indicated. 


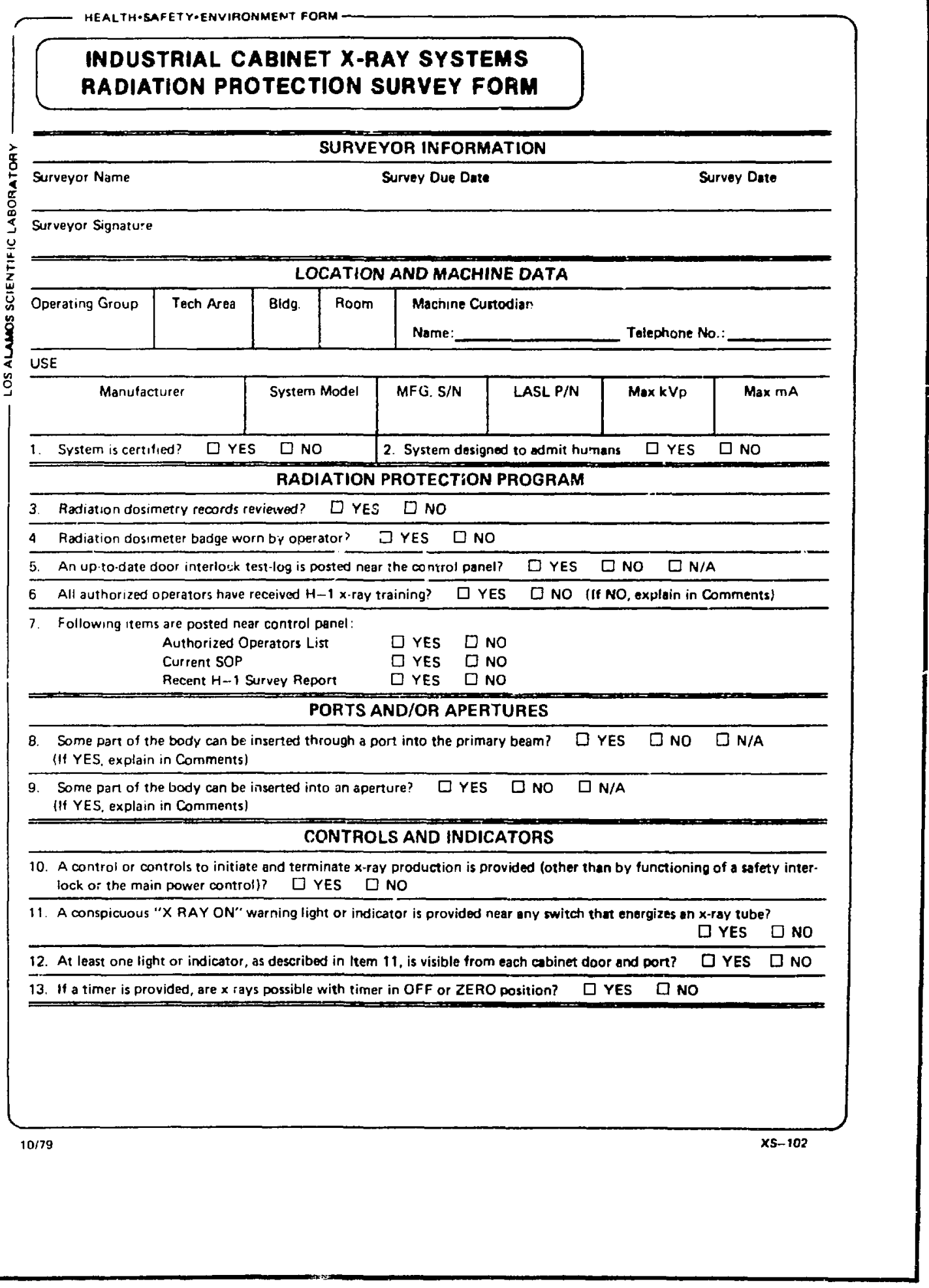




\section{SAFETY INTERLOCKS}

14. Are two interlocks or a physical disconnect and one interlock visible at ench door? $\square$ YES $\square$ NO $\square$ N/A

15. Did all doors and access panels tested interrupt or prevent $x \cdot$ ray production when open? $\square$ YES $\square$ NO $\square$ N/A

16. For cabinets designed to admit humans: Is the use of the " $X$ RAY ON" control necessary to resume opcration after opening and closing door? $\square$ YES $\square$ NC $\square$ N/A

\section{SYSTEM DESIGNED TO ADMIT HUMANS}

1\%. Is a control provided within the cabınet for preventing ard terminating $x$-ray production \{panic switchl? $\square$ YES $\square$ NO

18. Is it possible from outside the cabinet to override, reset, or brpass the panic switch? $\square$ YES $\square$ NO

19. Is it possible to initiate $x$-ray production from within the cabinet? $\square$ YES $\square$ NO

20. Are audible and visible warning signals contained within the cabinet which activate for at least 10 seconds just prior to $x$-ray production? $\square$ YES $\square$ NO $\square$ NOT DETERMINABLE

21. Does the visible warning signal inside the cabinet remain activated during $x$-roy production? $\square$ YES $\square$ NO $\square$ NOT DETERMINABLE

22. Are signs provided inside the cabinet indicating the meaning of the warning signais and panic switch? $\square$ YES $\square$ NO

\section{LEAKAGE RADIATION}

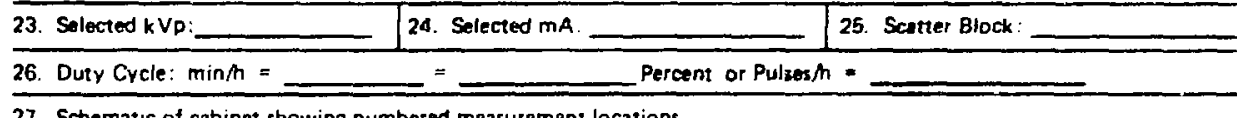

27. Schematic of cabinet showing numbered measurement locations. 


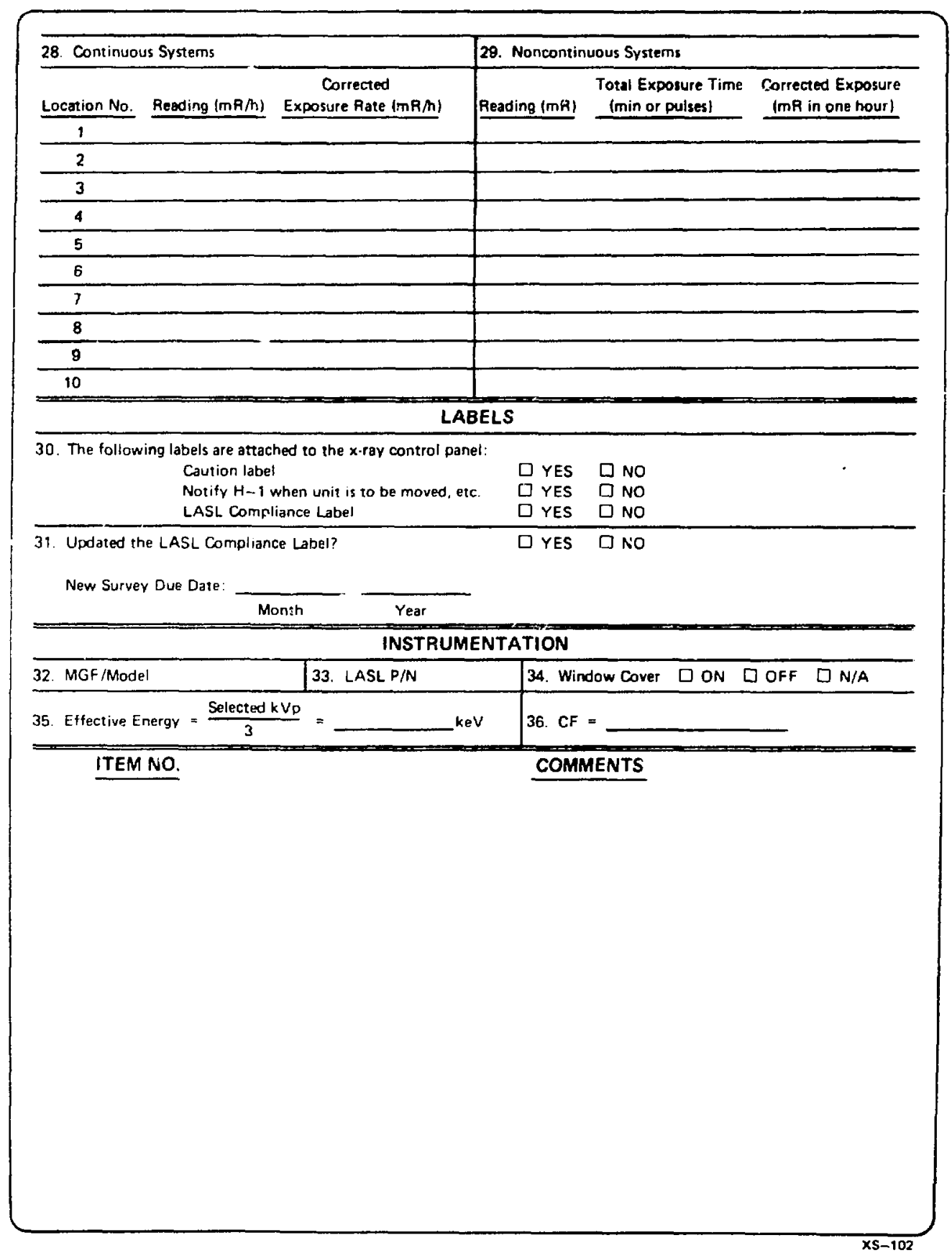




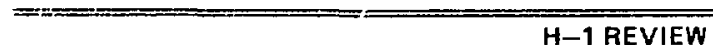

Section Leader :

$X$. Ray Control Office:

Oistribution: Origina! - Operating Group Leader

Xc: Machine Custodian (1)

Health Physics Section (1)

$\mathrm{X}$. Ray Control Office (1) 
This survey procedure is applicable to industrial noncabinet $x-r a y$ systems. Both mobile and fixed systems are included. It is designed to determine compliance of such systems with the applicable health and safety requirements in LASL's Health, Safety and Environment Manuzl. See Administrative Requirements $5-3$ and Technical Bulletin 532 (Appendix B) for applicable requirements.

Leakage radiation measurements should be performed with an ionization chamber whose energy dependence curve is known. See Appendix A for a compilation of energy dependence curves for many of the ionization chambers available at LASL. For mobile installations, leakage radiation measurements should not be performed during the survey because of the constantly changing machine location. They are, however, the responsibility of the machine operator at each exposure location. Assistance is available from Group $\mathrm{H}-1$ in setting up an open installation if requested by the operating Group. 
INDUSTRIAL NONCABINET X-RAY SYSTEMS

RADIATION PROTECTION SURVEY PROCEDURES

(For use with J.ASL Form XS-103)

1. Surveyor Information. Complete all items.

2. Location and Machine Data. Complete all items.

3. Radiation Protection Program

a. Item 1. Review the radiation dosimetry records of the past year for all authorized operators. Note any unusual trends in the comments section.

b. Iteins 2-3. Self-explanatory.

c. Item 4. See the machin. custodian and check his training documentation for each authorized operator. Note any discrepancies in the comments section.

d. Iten 5. Seli-explanatory.

4. Controls and Indicators

a. Item 6. Have the operator turn on power to the system. Have him set the $x$-ray control to the lowest selectable values of $k V p$ and $m A$. Is there an "x-ray on" control. provided which can energize and de-energize the $x$-ray tube? If so, respond "yes."

b. Item 7. If a timer is provided, set it in the OFF or ZERO position. Attempt to make $x$ rays. X-ray production should not be possible with the timer in an OFF or ZERO position.

c. Items 8-9. Momentarily energize the x-ray tube. Is a conspicuous warning light or indicator labeled with the words "X RAYS ON," or similar words located near any switch which energizes an $x$-ray tube? By conspicuous is meant a light or indicator of sufficient size and intensity and/or of a rotating or flashing type design. Walk over to every door; is a waming light or indicator, as described above, clearly vistble from each exposure room door? One light may satisfy the requirements of items 8 and 9 if 1 is close to both the door and the control panel.

Note that these lights or indicators must only be activated when $x$ rays are produced. That is, when high voltage is applied to the $x$-ray tube or when tube current flows. They should not be activated when only the line power switch is turned on.

d. Item 10. Open each door to see if two interlocks are visible around the door seal. 
e. Item 11. Only those access panels that do not require tools to open should be checked. Energize the $x$-ray tube and slightly open each door and access panel. Note whether $x$-ray production is terminated by observing the $\mathrm{mA}$ meter or waning light at the control panel. This is not possible with pulsed systems or machines with short exposire times. In' this case, slightly open each door and access panel separately and then attempt to initiate $x$-ray production.

f. Item 12. Fnergize the x-ray tube. Open each door and access panel separately and then close $i t$. Does $x$-ray production resume immediately or does the " $\mathrm{x}$ ray on" control or a suitable reset device have to be used to resume operation?

\section{X-Ray Rooms For Which Occupancy Cannot Be Easily Determined}

a. Items 13-14. Determine if a control is located within the room for preventing and terminating $x$-ray production (pantc or scram switch). Activate this control, proceed to the outside of the room, close the door, and determine if the control can be overriden, reset, or bypassed from the outside of the room. Try to produce $x$ rays. Once the panic switch is activated, it should require resetting inside the room before $x$ rays can be produced.

b. Item 15. There should be no way of initiating x-ray production from inside the room.

c. Items 16-17. Determine if audible and visible signals are contained within the room which are activated at least 20 seconds before $x$-ray production can be initiated. The visible warning signal should remain activated during $x$-ray production.

Note: Do not remain within the room to find out if the visible warning signal remains activated during $x$-ray production.

d. Item 18. Self-explanatory.

e. Item 19. A sign similar to the following should be provided inside the room:

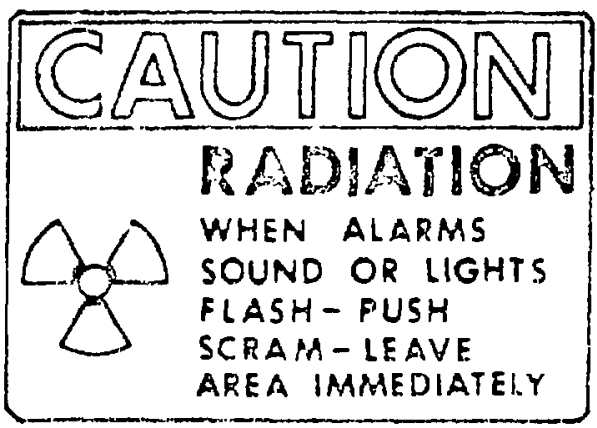




\section{Leakage Radiation Measurements}

a. Items 21-22. Have the operator set the $x$-ray control to the highest selectable $\mathrm{kV}_{\mathrm{P}}$ and to the highest $\mathrm{mA}$ allowed by the tube rating chart for the $k V p$ selected.

b. Item 23. Based on the x-ray tube rating chart or on information provided in the operating manual, determine the system's duty cycle for the selected $\mathrm{kVp}$ and $\mathrm{mA}$. Record the duty cycle either in minutes per hour or in pulses per hour as appropriate. Convert minutes per hour to percent by multiplying by $100 / 60$. For example, $10 \mathrm{~min} / \mathrm{hr} \times 100 / 60=16.67 \%$.

c. Iteiu 24. Whenever desired, an attached engineering drawing can be used to show numbered measurement locations.

d. Item 2b. The $x$-ray tube and beam direction should be positioned and oriented so that the highest exposure rate will be encountered in the area under test provided that such positioning and orientation will serve a practical purpose in normal usage and is not prohibited in the SOP. All worse case beam orientations allowed by the SOP should be investigated. No collimator or filter should be used during these tests unless they are permanently attached to the $x$-ray tube and the unit cannot be operated without them. Whenever the tube is not pointing toward a primary shield, a scatter block should be used. The dimensions of the scatter block should be at least equal to those of the $x$-ray field. For tube potentials in the range of $50-150 \mathrm{kVp}$, the optimum scatter block is about 3 inches of lucite, paper, or wood. For kigher tube potentials, any available low atomic number material may be used.

e. Item 26. By continuous systems is meant systems capable of exposure times greater than 10 seconds. For each beam orientation and area selected, scan the external surfaces of the enclosure at approximaiely $30 \mathrm{~cm}$ (1 foot) with an ionization rate meter. Record the maximum reading for each location. Correct the readings obtained by multiplying each reading with the duty cycle and dividing by the correction factor (CF) as follows:

Corrected Reading $(\mathrm{mR} / \mathrm{hr})=\frac{\text { (Reading) } \times \text { (Duty Cycle in Percent) }}{\text { CF } \times 100}$

f. Item 27. By noncontinuous or pulsed systems is meant systems not capable of exposure times greater than 10 seconds. Select several locations for each beam orientation that would appear to have the most significant leakage. 
TLDs w111 he used for radiation leakage measurements on noncontinuously activated systems (e.g., pulsed systems). Leakage will be integrated over a reasonable period of time. Arrangements should be made several days in advance of the survey date with the Health Physics Analysis Lab for the required TLDs. Consultation with the x-ray Control office and the Health Physics Analysis Lab is recommended for selection of TLD type and exposure duration.

Place a TLD packet at each selected location. Indicate on the schematic (Item 24) the packet number placed at each location. Have the operator integrate a sufficient number of exposures on the TLDs over a period of time. Record the total exposure time in minutes or pulses for each TLD packet. Have the TLDs analyzed and record the readings at Item 27. Correct the TLi readings as follows:

Corrected Exposure $(\mathrm{mR}$ in one hour $)=\frac{\text { (Reading) } \mathrm{x} \text { (Duty Cycle) }}{\text { (Total Exposure Time) }}$

where the duty cycle is expressed either in min/h or pulses/h and the total exposure time in either minutes or pulses.

7. Installation Classification

Item 28. See TB-532 for information on installation classification,

All fixed Installations must meet the requirements of either a protective or an enclosed installation. The difference between the two classes is in the allowed radiation emission limits: $0.5 \mathrm{mR}$ in any one hour at any accessible region $5 \mathrm{~cm}$ from the outside surface of the enclosure for protective installations; and $10 \mathrm{mR}$ in any one hour at any area accessible during irradiation $30 \mathrm{~cm}$ from the external surface of the enclosure for enclosed installations. For low kilovoltage x-ray tubes, small enclosures, and/or low workloads, the additional shielding required to achieve the protective installation exposure limit $(0.5 \mathrm{mR}$ in 1 hour at 5 $\mathrm{cm}$ ) may be economical, and if so should be recommended.

Only mobile or portable x-ray equipment should be used as an open installation. However, mobile or portable equipment that is always used in the same location should be considered as a fixed installation and be made to meet the requirements of a protective or an enclosed installation.

Keep in mind that compliance with the above facility emission liuits does not necessarily guarantee compliance with the maximum pertissible dose 1 Imits (see TB-502). Reasonable conditions of occupancy and use are relied upon to limit exposure to below the applicable dose limit. For example, an occupied area in an enclosed installation where the exposure rate is only $5 \mathrm{mR} / \mathrm{hr}$ will not meet the occupational dose limit when the workload is over 20 hours/week. In such a case, either the workload or the occupancy must be restricted by the SOP, or the shielding thickness increased. Review the radiation survey results on the basis of occupancy and workload. Multiply the exposure rate $(\mathrm{mR} / \mathrm{hr}$ ) by the workload (hr/week) 
and the occupancy factor to determine if the applicable weekly dose limi: is met for the area in question. The following occupancy factors should be used:

\section{OCCUPANCY FACTORS (T)}

Ful1 occupancy ( $T=1)$
$\begin{aligned} & \text { Control space, darkrooms, workrooms, shops, offices, corridors } \\ & \text { large enough to be used as working areas, rest and lounge rooms } \\ & \text { routinely used by occupationally exposed personnel, living quar- } \\ & \text { ters, children's play area, occupied space in adjoining buildings. }\end{aligned}$
Partial occupancy $(\mathrm{T}=1 / 4)$

Corridors too narrow for desks, utility rooms, rest and lounge rooms not used routinely by occupationally exposed personnel, elevators using operators, unattended parking lots.

Occasional occupancy $(T=1 / 16)$

Closets too small for future occupancy, toilets not used routinely by occupationally exposed personnel, stairways, automatic elevators, outside areas used only for pedestrians or vehicular traffic.

8. Labels and Signs

a. Items 29-31. Self-explanatory.

b. Item 32. Perimeters of radiation areas must be posted with "CAUTION: RADIATION AREA" signs. Based on the radiation survey results, are there any areas accessible to personnel with ocrrected radiation readings of $5 \mathrm{mR}$ in 1 hour or greater? If so, are they posted?

c. Item 33. Self-explanatory. 
d. Item 34. Al1 accessible areas found to exceed the $10 \mathrm{mR}$ in any one hour emission limit must be provided with elther positive means to deny access to these areas during irradiation or additional shielding to reduce the exposure to below the specifled limit. By positive means to deny personnel access is meant such things as fencing and locked or Interlocked gates and doors.

e. Item 35. The new survey due date you should select depends on the type of deficiencies found during the present survey.

\begin{tabular}{ll} 
& \multicolumn{1}{c}{ Resurvey Due Date } \\
\cline { 2 - 2 } $\begin{array}{l}\text { Mo deficiencies } \\
\text { (e.g., labeling, defective }\end{array}$ & 1 year from present survey \\
warning light) & 3 months from present survey \\
$\begin{array}{l}\text { Major deficiencies } \\
\text { (e.g., defective door inter- } \\
\text { locks, inadequate shielding) }\end{array}$ & DO NOT update label
\end{tabular}

For systems with minor deficiencles, plan to resurvey within three months-but only after the machine custodian informs you that all corrective actions have been completed. During the resurvey only check to see that all deficlencles have been corrected and if so, extend the new survey date by another nine months. Send a memo describing the 3-month resurvey results to the machine custodian with copies to the responsible $\mathrm{H}-\mathrm{l}$. HP and the X-ray Control office.

If In your judgement, however, major hazards need correction, you should effectively pull the piug by not updating the label. Discuss this action with the machine custodian and request him to call you for a resurvey when all corrections have been accomplished.

9. Instrumentation

a. Items 36-38. Self-explanatory.

b. Items 39-40. Estimate the effective energy of the $x$-ray fleld as a third of the selected $\mathrm{kVp}$. Determine the Correction Factor (CF) for the meter and window cover based on this effective energy. Consult LASL report LA-4052 or the calibration sheets provided with the survey meter for the appropriate CF.

10. Comments Section

Any necessary explanations or clarifications should be recorded here. 
11. Recommendations

Recommendations may be made by the surveyor, the Health Physics Section Leader, or the X-Ray Control office. Recommendations should be initialed by the person making them. If there are none, so state.

\section{H-1 Review}

The survey report will be reviewed by the responsible Health Physics Section Leader and the $X$-Ray Control office. The reviewers should sign the form where indicated. 
- HEALTH.SAFETY-ENVIRONMENT FOAM

\section{INDUSTRIAL NONCABINET X-RAY SYSTEMS RADIATION PROTECTION SURVEY FORM}

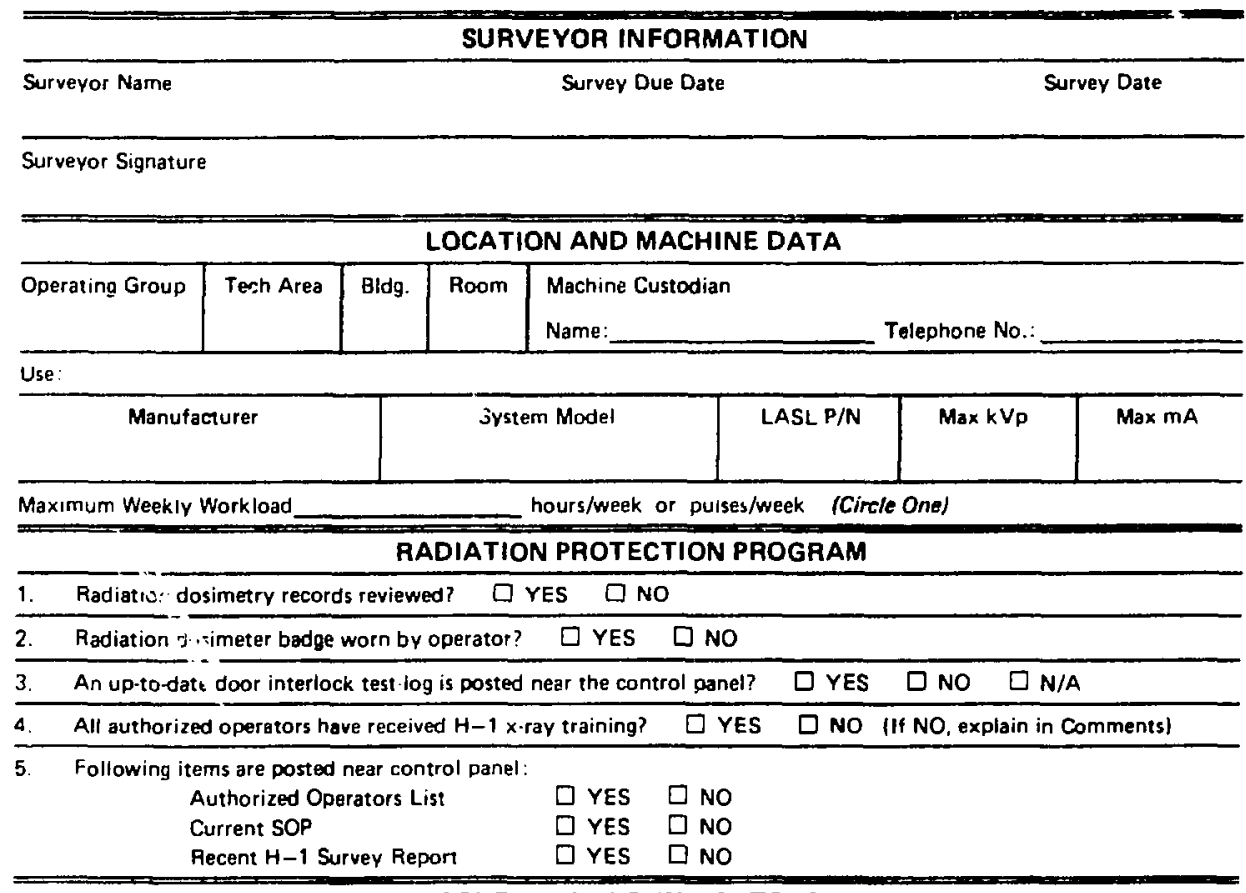
CONTROLS AND INDICATORS

6. A control or controls to initiate and terminate $x$-ray production is provided lother than by functioning of a safety interlock or the main power controll? $\square$ YES $\square$ NO

7. If timer is provided, are $x$-rays possible with timer in OFF or ZERO position? $\square$ YES $\square$ NO

B. A conspicuous " $X$ A $~$ C $O N$ " warning light or indicator is provided near any switch that energizes an $x$-ray tube? $\square$ YES $\square$ NO

9. At least one light or indicator, as described in Item 8, is visible from each exposure room door? $\square$ YES $\square$ NO

10. Are two interlocks visible at each door? $\square$ YES $\square$ NO $\square$ N/A

11. Do doors and access panels interrupt or prevent $x$-ray production when open? $\square$ YES $\square$ NO

12. Is the use of the " $X$ RAY ON" control or a reset device necessary to resume operation atter opening and closing a door? $\square$ YES $\square$ NO 


\section{X-RAY ROOMS FOR WHICH OCCUPANCY CANNOT BE EASILY DETERMINED}

13. Is a control provided within the room for preventing and terminating $x$-roy production (panic or ccram switch)?

$\begin{array}{r}\square \text { YES } \square \text { NO } \square \text { N/A } \\ \hline\end{array}$

14. Is it possible trom outside the room to override, reset, or bypass the panic switch? $\square$ YES D NO $\square$ N/A

15. Is it possible to initiate $x$-rey production from within the room? $\square$ YES $\square$ NO $\square$ N/A

16. Are wodible and visible warning signals contained within the room which activate at least 20 seconds before $x$ rays can be initiated? $\square$ YES $\square$ NO $\square$ N/A

17. Doos the visible warning signal inside the room remain activated during $x$-ray production? $\square$ YES $\square$ NO $\square$ N/A $\square$ NOT DETERMINABLE

18. Is "DANGER-HIGH AADIATION AREA" sign activated inside the room in conjunction with the warning signals? $\square$ YES $\square$ NO $\square$ N/A

19. Are signs provided inside the room explaining the meaning of the warning signals and panic switch?

$$
\square \text { YES } \square \text { NO } \square \mathrm{N} / \mathrm{A}
$$

20. Are suitable means of exit provided so that anyone eccidentally shut in can leave the room without delay?

$$
\square \text { YES } \square \text { NO } \square \text { N/A }
$$

\section{LEAKAGE RADIATION MEASUREMENTS}

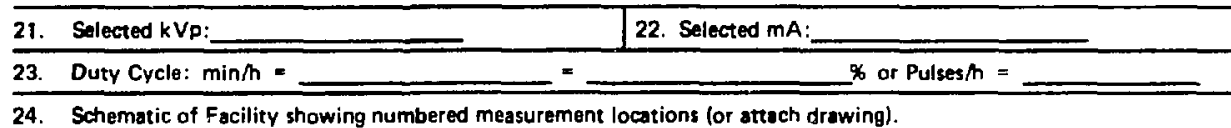




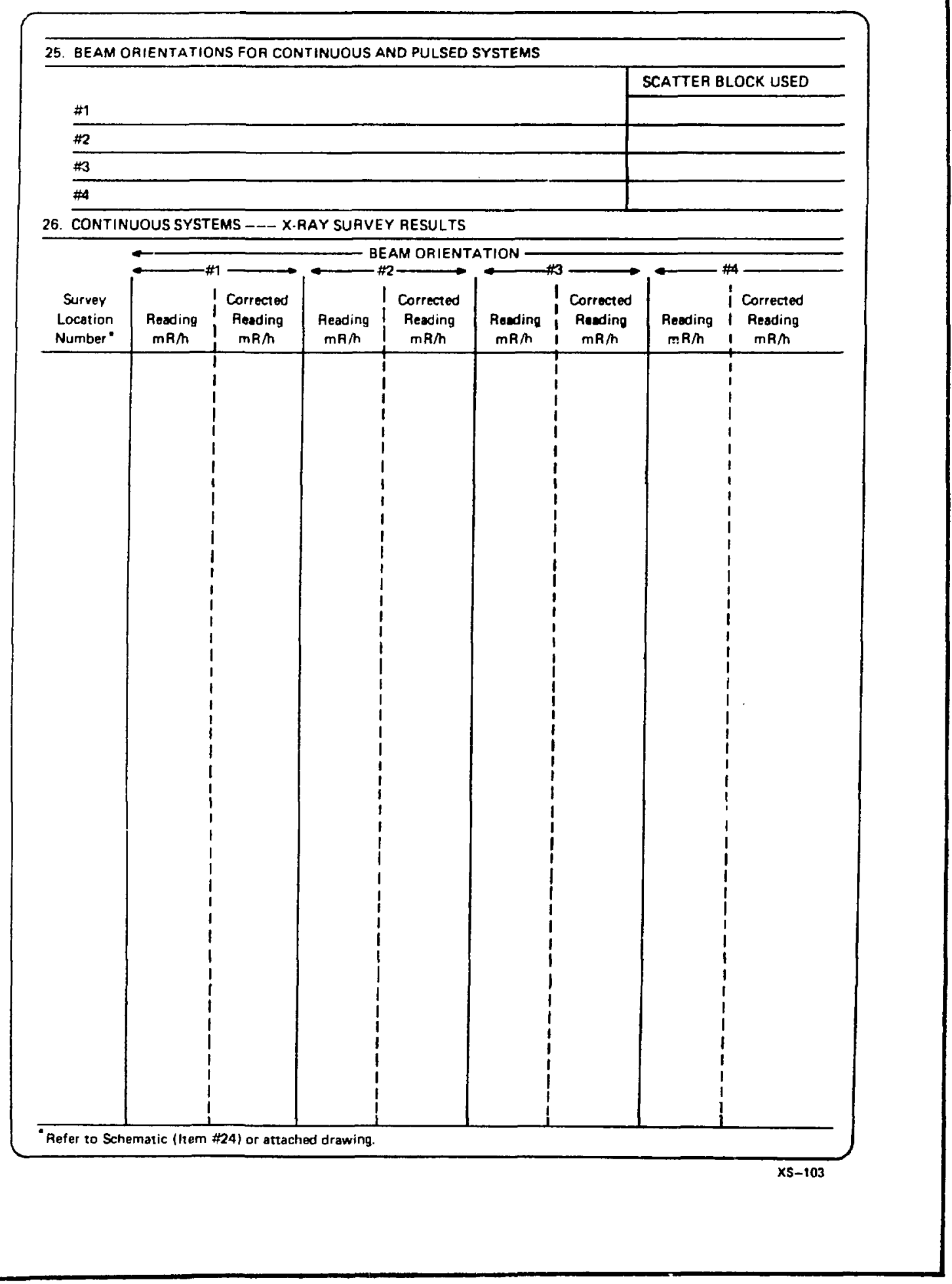




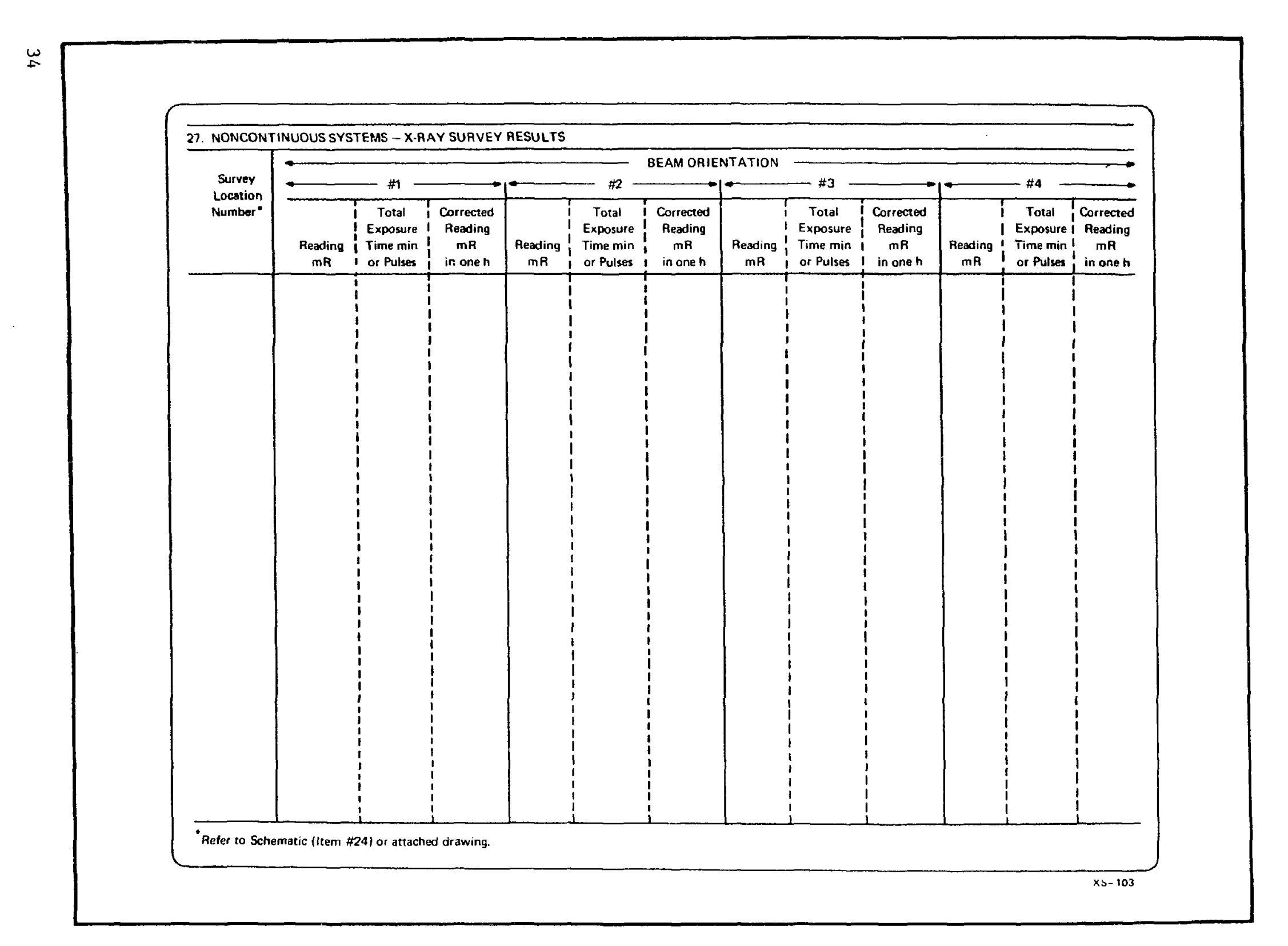




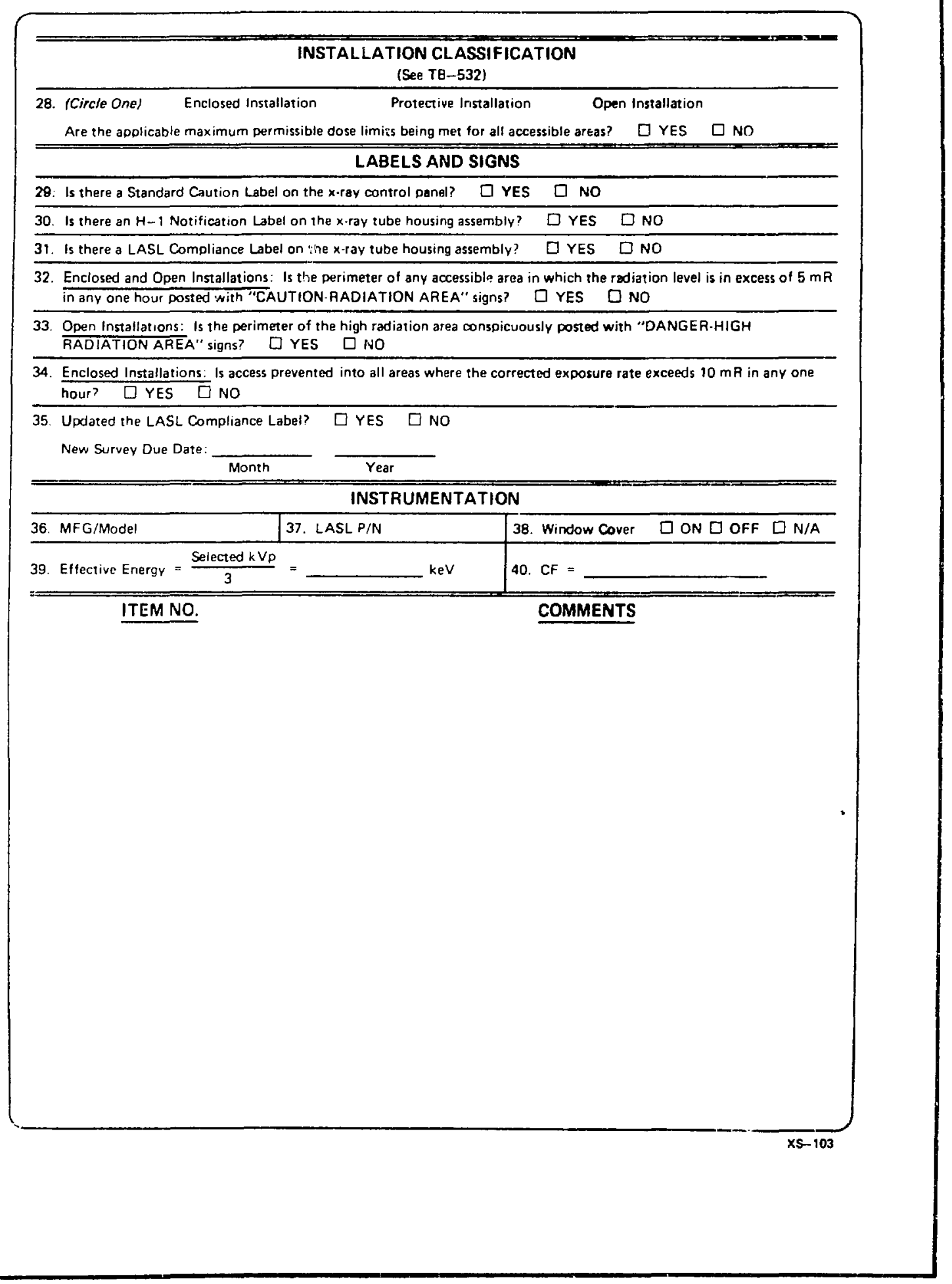


Section Leader

$X$-Ray Control Otfice:

Distribution: Original - Operating Group Looder

Xc - Machine Custodian (1)

Health Physics Section (1)

$X$.Ray Control Office (1) 
This survey procedure is applicable to electron microscopes and may also be used for electron microprobe analyzers. It is designed to determine compliance of such systems with the applicable health and safety requirements in LASL's Health, Safety and Environment Manual. See Administrative Requirements $5-3$ and Technical Bulletin 530 (Appendix B) for applicable requirements.

Because beams of small cross section may be encountered during exposure rate measurements around these devices, an ionization chamber with a cross-sectional area no larger than $10 \mathrm{~cm}$ should be used (e.g., the Victoreen Model 440RF/C). The use of a thin-window Geiger counter is recommended, however, for detecting or localizing radiation beams. After the beam is detected with a Geiger counter, the ionization chamber should be used to obtain a quantitative measurement since readings obtained with the Geiger counter in the soft $x$-ray range are unreliable. 
ELECTRON MICROSCOPE

RADIATION PROTECTION SURVEY PROCEDURE

(For use with LASL Form $\mathrm{xS}-104$ )

1. Surveyor Information. Complete all items.

2. Location and Machine Data. Complete all items.

3. Radlation Protection Program

a. Item 1. Review the radiation dosimetry records of the past year for all operators. Note any unusual trends in the Comments section.

b. Items 2-3. Self-explanatory.

4. X-ray Leakage Measurements

a. Items 4-7. Have the operator set up the microscope to maximize x-ray leakage:

(1) maximum accelerating voltage and beam current normally used (record at items 4 and 5);

(2) a dense specimen with the highest atomic number being studied (describe in item 6);

(3) Low magnification--typically 5,000X (record selected magnification in item 7); and

(4) if possible, the beam at cross-over on the specimen.

b. Items 8-12. Self-explanatory.

c. Items 13-14. With the microscope energized, use a thin window GM counter to scan all external surfaces. Areas to be scanned should always include:

(1) Gun

(2) Viewing chamber

(3) camera

(4) Specimen chamber door and column

(5) High voltage transformer tank

The inside of compartments next to or under the electron beam column should also be scanned - but only if their access panels can be opened without tools. 
Select several locations with significant readings for quantitative evaluation. Draw a schematic of the microscope in Item 13 showing these selected locations and number each location selected. Place a Victoreen 440 RF/C at each of these locations and measure the exposure rate. Record the results and thr appropriate range correction factors in Item 14. Correct the recorded exposure rates by multiplying with the range correction factor and dividing by the energy correction factor.

d. Item 15. If the exposure rate inside any of the compartments checked exceeded $5 \mathrm{mR} / \mathrm{hr}$, the corresponding access panel must be interlocked to prevent or interrupt beam production when open.

5. LASL Compliance

a. Item 16. The new survey due date you should select depends on the type of deficiencies found during the present survey:

\section{Resurvey Due Date}

No deficiencies

Minor deficiencies

(e.g., labeling)

Major deficiencies

(e.g., inadequate shielding)
1 year from present survey

3 months from present survey

DO NOT update label

For systems with minor deficiencies, plan to resurvey within three months - but only after the machine custodian informs you that all corrective actions have been completed. During the resurvey only check to see that all deficiencies have been corrected and if so, extend the new survey date by another nine months. Send a memo describing the 3-month resurvey results to the machine custodian with copies to the H-l Section Leader and the X-ray Control office.

If in your judgement, however, major hazards need correction, you should effectively pull the plug by not updating the label. Discuss this action with ihe machine custodian and request him to call you for a resurvey when all corrections have been accomplished.

\section{Comments}

Any necessary explanations or clarifications should be recorded here.

\section{Recommendations}

Recommendations may be made by the surveyor, the Health Physics Section Leader, or the X-ray Control office. Recommendations should be initialed by the person making them. If there are none, so state. 


\section{8. $\mathrm{H}-1$ Review}

The survey report will be reviewed first by the responsible Health Physics Section Leader and then by the X-ray Control office. The reviewers should sign the form where indicated. 


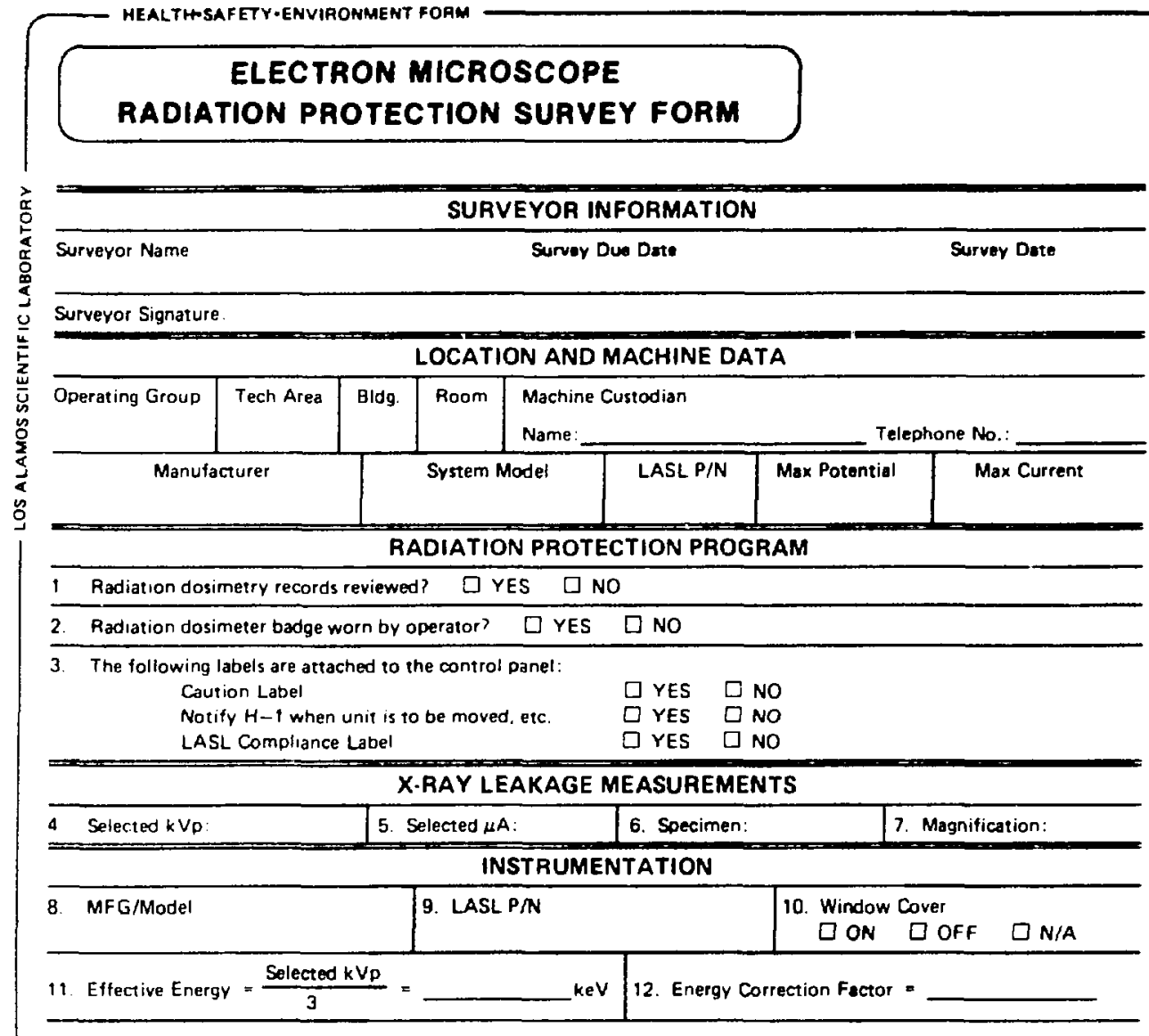


13. Schematic of microscope showing mesurement locations:

14

Microscopes $<200 \mathrm{kVp}$ : Exposure rate must not exceed $0.5 \mathrm{mR} / \mathrm{h}$ from any accessible external surface.

Microscopes $>200 \mathrm{kVp}$ : Exposure rate must not exceed $2.5 \mathrm{mR} / \mathrm{h}$ from any accessible external surface.

Inside compartments whose access panels are not interlocked: Exposure rate must not exceed $5 \mathrm{~mA} / \mathrm{h}$.

15. Are all eccess panels presenting a potential radiation hazard interlocked to prevent or interrupt beam production when open? $\square$ YES $\square$ NO 


\section{LASL COMPLIANCE}

16. Updated the LASL Compliance Label?

$\square$ YES $\square$ NO

New Survey Due Date:

Month

\section{H-1 REVIEW}

Section Leader :

X-Aay Contral Office:

Distribution: Original -Operating Group Leader

Xc: Machine Custodian (1)

Health Physics Section (1)

X-Ray Control Office (1) 
$\begin{array}{lllllllll}A & P & P & E & N & D & I & X & A\end{array}$

Energy Dependence Correction Factors 




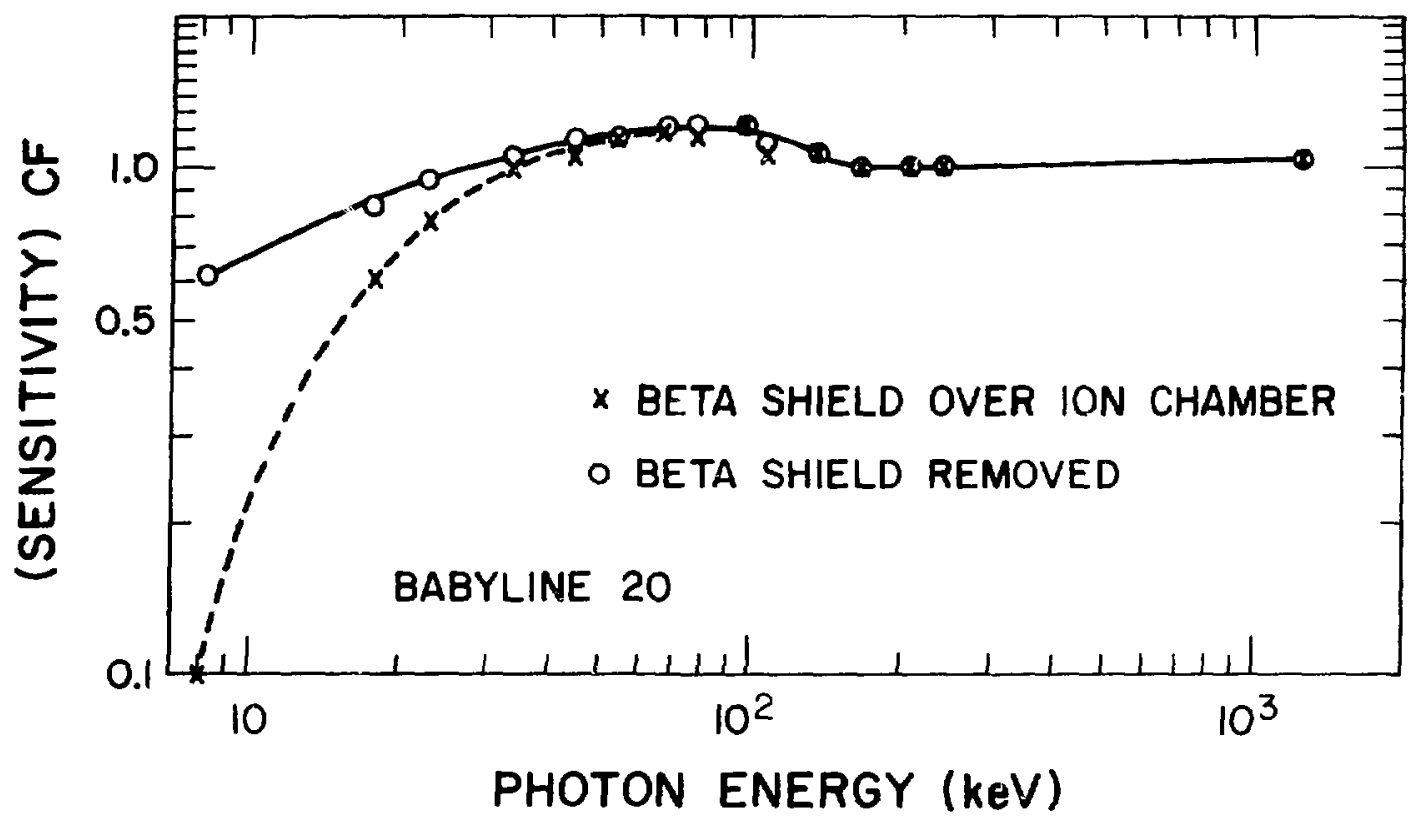

EBERLINE INSTRUMENT MODEL NUMBER RO-5B

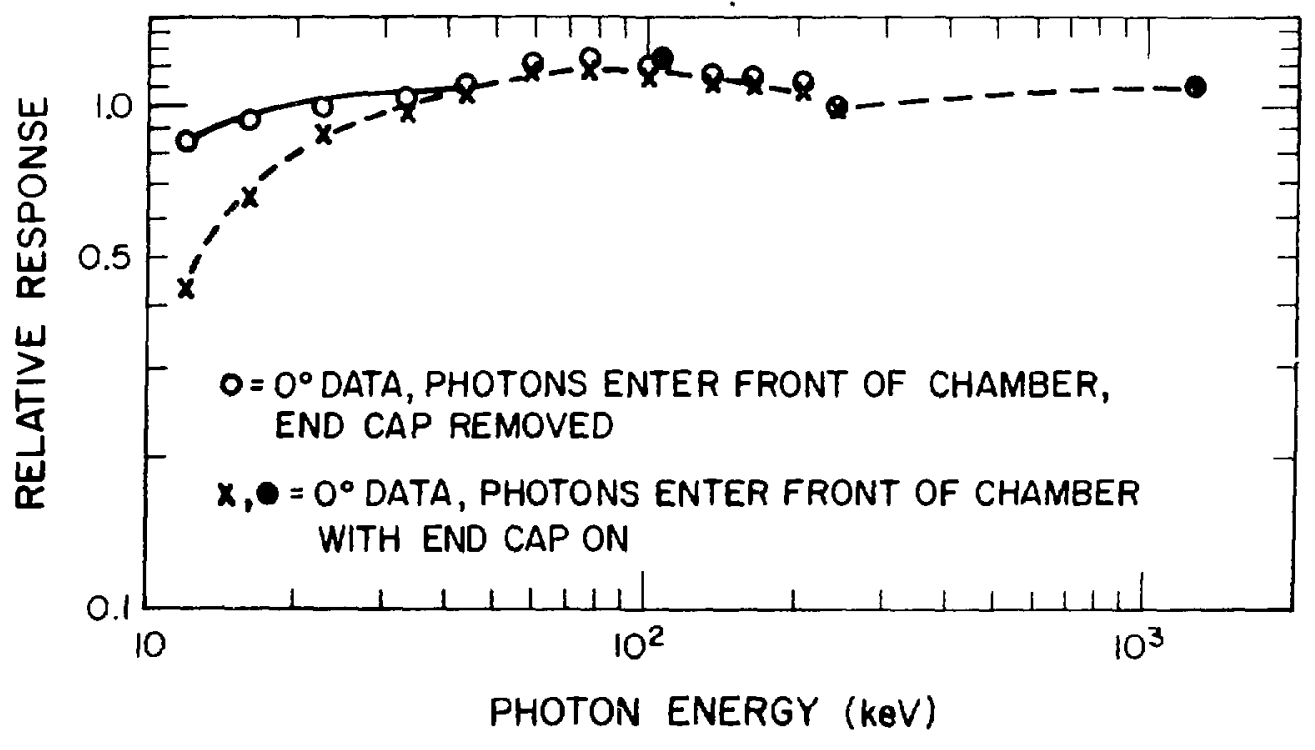


EBERLINE INSTRUMENT MODEL NUMBER RO-5B

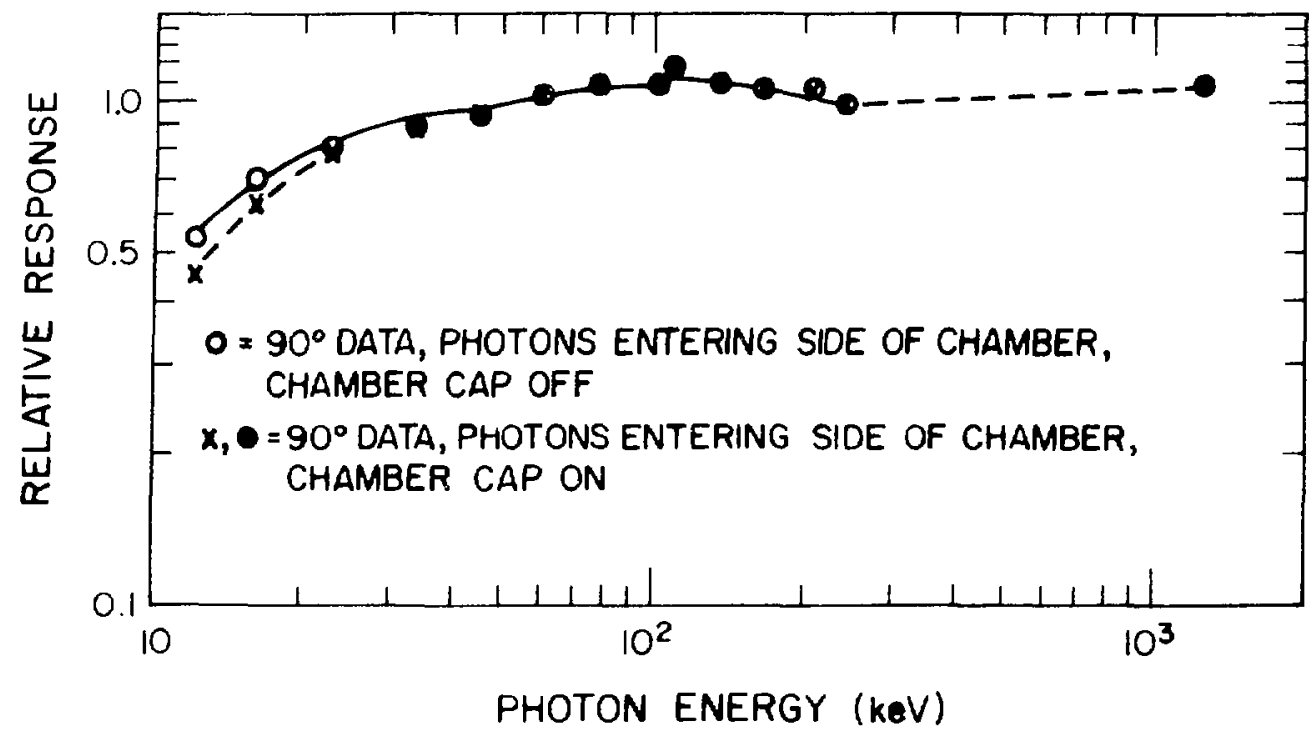

EBERLINE INSTRUMENT MODEL NUMBER RO-5C

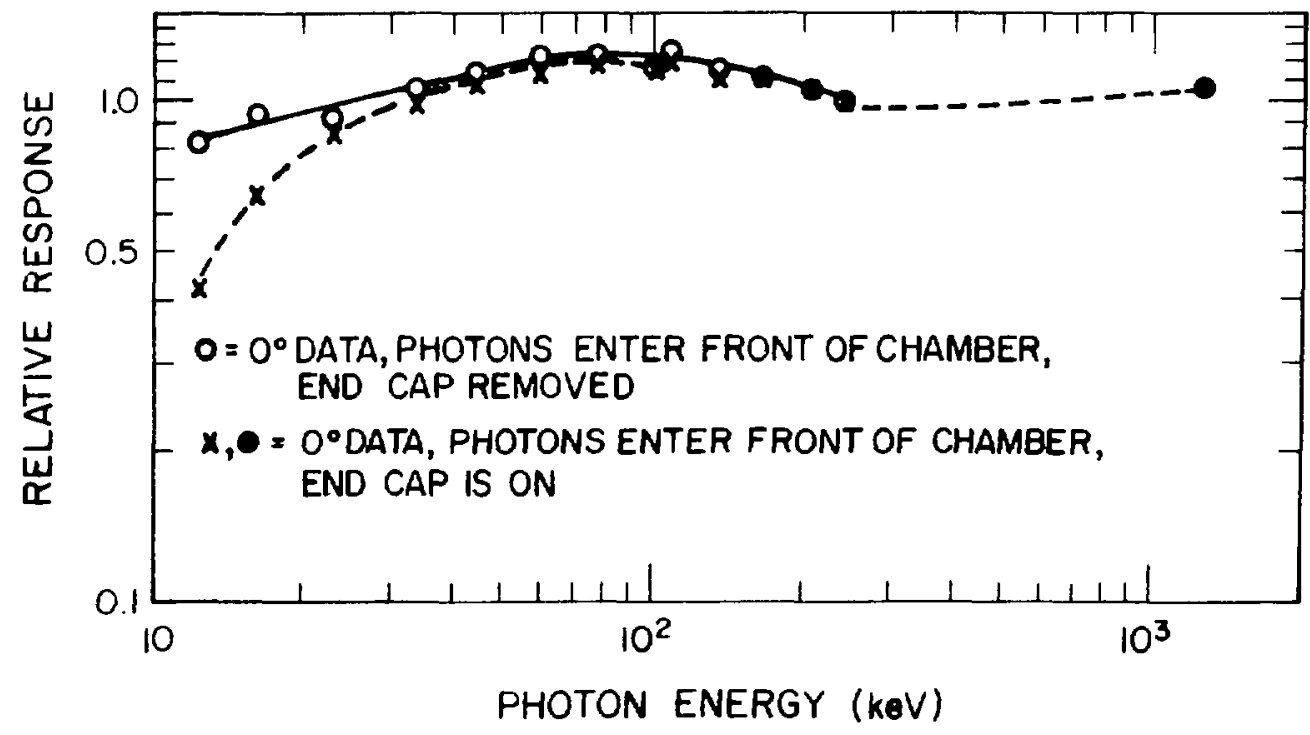


EBERLINE INSTRUMENT MODEL NUMBER RO-5C

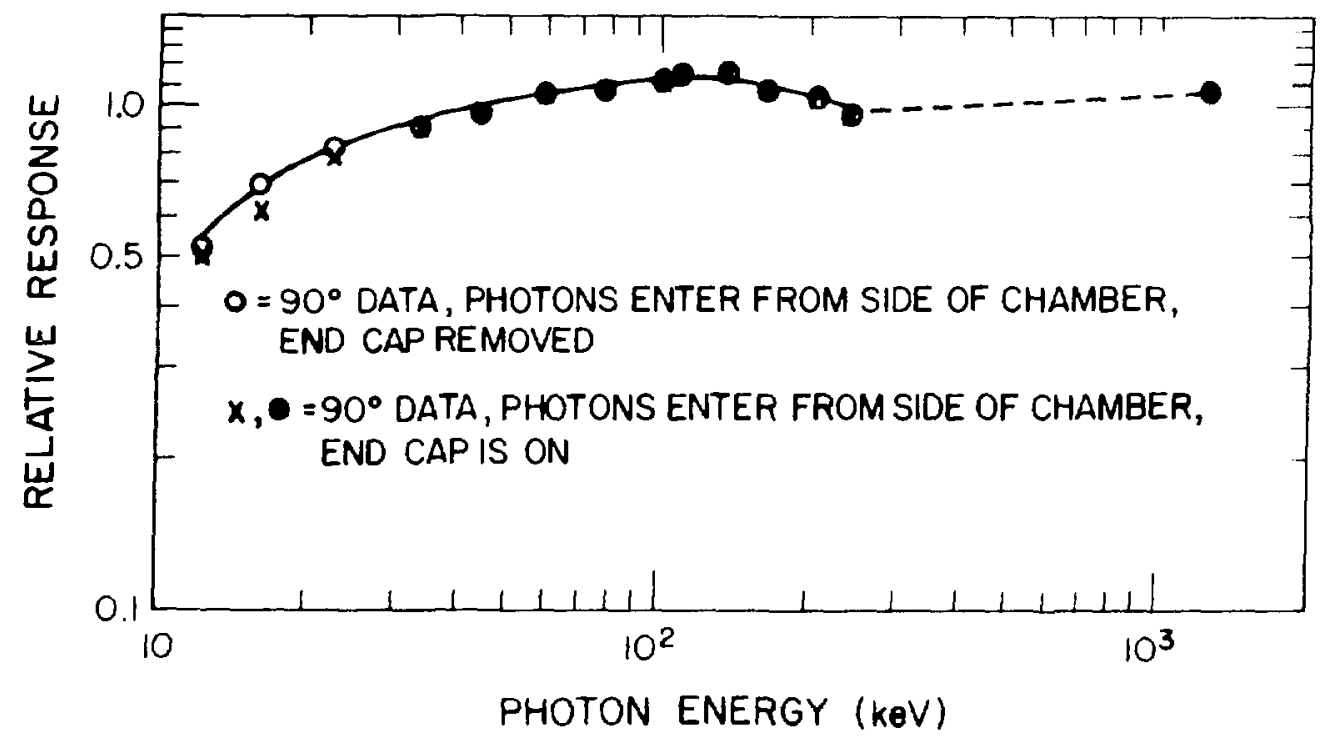


$\begin{array}{llllllllllllll}A & P & P & E & N & D & I & X & B\end{array}$

LASL X-ray Device Control Program 


\section{ADMINISTRATIVE REQUIREMENTS}

\section{X-RAY GENERATING DEVICES}

\section{INTRODUCTION}

This document establishes the safety program for $x-$ ray generating devices used at LASL. It describes the -equirements and responsibilities for registration, safety systems, radiation surveys, personnel dosimetry, standard operating procedures, operator training, and user control. Details concerning specific safety features and technical requirements for various types of $x-r a y$ devices are given in the Technical Bulletins as referenced. $x$-ray generating devices covered by this document include $x$-ray diffraction and $x$-ray fluorescenze analysis systems, electron microscopes, Febetrons, industrial $x-r$ ay systems, medical $x-r a y$ machines, veterinary $x-r$ ay systems, and experimental devices capable of generating $x$-rays. However, two broad categories of $x-r a y$ generating devices are recognized: intentional (e.g., x-ray diffraction and industrial $x-r a y$ equipment) and incidental (e.g., electron microscopes, high voltage electron guns, electron beam welding machines, Jennings switches, and other high voltage switches). The applicable requirements for a given $x$-ray device depend on whether it is intentional or incidental.

\section{REFERENCES}

Health, Sarety and Environment Manual, "Standard Operating Procedures and Special Work Permits," Administrative Requirements $1-3$, Los Alamos Scientific Laboratory manual LA-7940-M. 
Health, Safety ant Environment Marda., "Pajiation

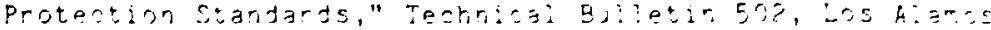

solentirle Laboratory rianda: LA- $\$ 4 ;-M$.

Health, Sarety art Environmert Manua?, "Analytica: $x_{1}=$ :

Devices," Technical Bulletin 530, Los Aiamos Saiert:?:

Labaratory manua? LA-79L9-".

Heaith, Safety and Environment Manda:, "Industrat

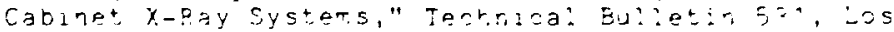

Alamos Seientif le Laboratory marial LA-7940-W.

Hea?th, Sarety and Environment Manua?, "Irdustria?

Noncatinet X-Ray Irstallations," Techrical Bujietir =: :

Los Alamos Soientifle Laboratory manua? LA-7945-M.

\section{DEFINITIONS}

X-Ray Device Control office - A unit in the Hea?th Physics Group (H-T) that is responsible for estabis inir. requirements and standards for the Laboratory's $x-r a y$ generating device control progran.

Machine Custodian - An indivitual designated by tho operating division/group who is responsibie for specis: $x \rightarrow r a y$ generating devices.

Authorized Operators - Individuals designated by the Machine Custodian who are qualified because of trainiraz and experience to use the $x$-ray equipnent.

LASL Compliarce Label - A label afrixed to the $x-r a y$ generating device certirying that the machine has beer. surveyed and that appropriate safe operating requirements have been met (see Fig. 1).

\section{LASL X-RAY COMPLIANCE}

This machine has been surveyed by $\mathrm{H}-1$ and

found to meet all applicable radiation

mety tondards and operational safety roquirements.

Contact $\mathrm{H}-1$ prior to the date below for - resurvey of this machine.

Survey expiration date:

Month Year

Fig. 1. LASL x-ray complience label.

Page 2 of 8 
Intentional X-Ray Device - A device that is designed to erit x rays ror a particular application. This term is synonymous with "x-ray equipment."

Incidenta? X-Ray Device - A device that emits or produmes external $x$ rays incidentaliy to its operation. $x$ rays: this case are an unwarted by-product of its intended design purpose.

\section{REQUIREMENTS FOR INTENTIONAL X-RAY DEVICES}

1. All devices and new facility shielding must be approved by $\mathrm{H}-1$.

2. A:l devices and each $x-r a y$ tube housing in use mus: be registered with the $x$-Ray Device Control office.

3. An SOP and a currently valid LASL compliance labe: are required for the operation of intentional $x$-ray devices.

4. LASL rasiation dosimetry badges must be worn by a?? personnel involved in $x-r a y$ work, in addition to any speaia: dosimetry required.

5. Only authorized operators, whose names are posted at the location of the device, are permitted to operate $x$-ray equiptient.

5. Operators (other than medical $x$-ray technicians) must receive the $H-1 X$-Ray Safety Training and be trained in the sops and safety system features associated with the $x-$ ray equipment.

7. All enclosure door safety interlocks on industrial $x-r a y$ equipment must be tested semi-annually, with test documentation posted at the location.

8. Intentional $X-r a y$ devices must be surveyed periodically and following any modifications to the equipment. Records of all equipment modifications must be maintained.

9. Maintenance, repair, or nonroutine work which may expose personnel to the primary beam requires prior $H=1$ approval.

10. All devices inust be used in a manner that maintains personnel exposure as low as practicable (ALAP) and within the occupational exposure limits.

Page 3 of 8 
REQUIREMENTS FOR INCIDENTAL X-RAY DEVICES

1. Incident3? x-ray deviees wi:r. azcejerating poter:ia:s ir exzess of 45 kilovo:ts must be surveyed at less: onco. Regijomants for sijelizig, personnel dosime:ry, arz resurvey frequency wi:l be detarm: rat by $\mathrm{H}^{-}$on a case-by-case basis.

2. LASL rajiat:or. Josimetry badzes nust be worn by electron microsiopists $37 \%$ in other situations as prescribez $5 ; \mathrm{H}-1$.

3. All electrom. microszopes must be reglsterej with the X-Ray Device Control orfice.

4. A currently valif LASL compiance label is required for the operation of electron microscopes.

\section{RESPONSIBILITIES}

\section{Intentiona? $x$-Ray Devices}

Operating graups are responsibie for complying with the applicabie requipements of this document, including the regist-ation of a: : devizes within the group, the appointment of manhine custotians, preparation of SEPs. ant verif $2=3$ tion of operator qualification and training.

Machine custodians are responsible for maintaining and posting the list of authorized operators, arranging for all necessary operator training, for conducting, documenting, and posting door interlock tests, and for notirying $\mathrm{H}-1$ or repairs, modifications, or relosation of $x$-ray equipment and resurvey needs.

Authorized operators are responsible for complying with all operational requirements as specified in the SOPs, and for notifying the machine custodian and $\mathrm{H}-1$ of a known or suspected radiation accident/incident.

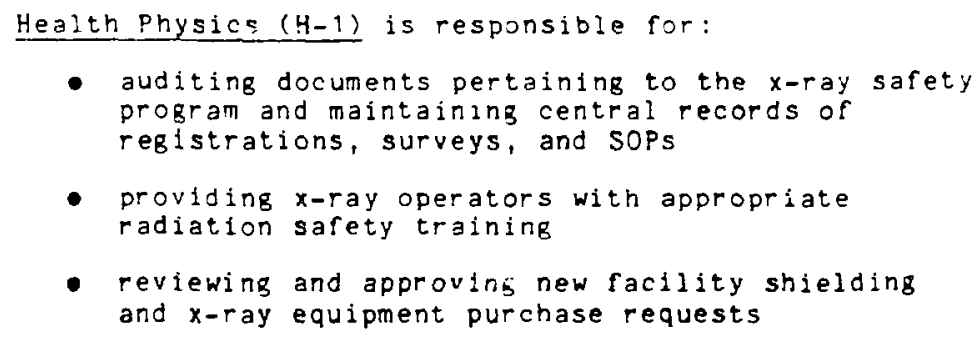

- auditing documents pertaining to the $x$-ray safety program and maintaining central records of rebistrations, surveys, and sops

- providing $x$-ray operators with appropriate radiation safety training

- reviewing and approvins new facility shielding and $x-r$ ay equipment purchase requests 
- providing planaing and consuliation servizes :the operating group

- performing annual radzat:or surveys, rojiza monicoring, and special surveys, as needed.

The Procurement Group (SP-ij) is responsibie foforwarjing al? purchase reaues s for amplete x-ray systems to H-l for 3 oprova?.

\section{In:ider:a? $x$-Ray Devices}

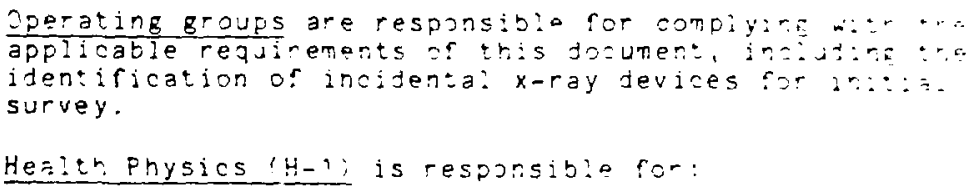

- performing injtza? and periodic rajiation sumar as neoded

- provising consjitation to the oporatige grati

- reviewing and approving shie:jing add:tiors ar mo. if is a: :sr.s.

\section{PROCEDURE}

\section{Approval of $x$-Ray Devices/Facility Shiezding}

SP-19 sends all purchase requests for $x-r a y$ equipnent to H-l for review and approva! prior to purahase (puratiasa requests for replacement or spare components and parts should not be sent to $H-1$ ). H-t will routinely approve only those intentional $x-r a y$ devices that meet al? applicable provisions and technica: requirements specified in the referenced Technical Bulletins addressing $x$-ray devices, systems, and insta? ations. For devices not covered by these Technical Bulietins, contact the $x-R a y$ Device Control of ice $(7-3354)$ for assistance and specific instructions.

Prior to putting a new facility or machine into service, H-1 makes a complete radiation survey to ensure that the machine meets the applicable standard as set forth in the Technical Bulletins. Planning and consultation sessions between $\mathrm{H}-\mathrm{l}$ and the operating group are necessary to examine the radiation safety features and requiremenis for new machines and new locations.

Page 5 of 8 


\section{Registration of Devices}

Fom HSAE 5-3A should be compieted and riled with $\mathrm{H}-$ ! : rezister al: electron microscopes, intentional $x-r a y$ Jovicos ant eant $x-r a y$ cube housing in use. Contaat tre Hoa:th physics representative for assistance if neassary.

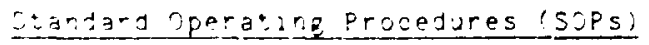

Tha frocedure for the preparation, review, and approva: of SOPs is deszrlbed in AJministrative Requirements ? - , "Iandard jperating Procedures and Special work Permits." In afdition to the requirements stated in this documert, Eps io intentional $x-r$ ay devices should also include the rollowing as appropriate:

- normal oporati-g procedures

- alignment proceduris

- sample handiing procejures

- Jesaription of al! safety hazards--inciuding radiation

- description of machine safety features (interloaks, warning signals, etc.)

- posting of signs and labels

- description and use of equipment

- machine safety checklist.

The SOP should be posted near the $x$-ray device control panel. It must represent the actual operating procedure and show the date of the last annual review.

\section{LASL Compliance Label}

This label (see Fig. 1) is affixed to the $x-r a y$ device by $\mathrm{H}-1$ after the device has been approved, a radiation protection survey performed, and after it has been verified that the requirements of this document have been met. The label is valid for a limited period of time as indicated by the survey expiration date at the bottom of the label. The machine custodian should contact $\mathrm{H}-1$ prior to the expiration date for a new survey and revalidation of the compliance label.

Devices at variance with one or more of the applicable Technical Bulletin requirements may be permitted to operate if:

- comparable radiation safety is achieved through alternate means

Page 6 of 8 
- a necessary funztion or an intended purpose azr: be performed or aczompilshed with the de:ize meeting al: of the app?icable requirements.

A specia? work permit will be regultoj ror these casas.

\section{Personnel Dosimetry}

In adjition to dositetry badges, H-t may require sper: dosimetry devices such as fjnger rings, pocket.

Josimeters, or chirpers. The use of suat deices must to specified in the SOP.

\section{Authorized Operators/Personnel Training}

The operating group should appoint machine custodiars ror all intentional $x$-ray devices within the group. The machine custodian should maintain a list of operato:s wha are qualified to use $x-r a y$ equipment beause of trainime and experience and who are designated as authorized operators for particular machines. The machine custodiar. should also maintair documentation of each individua?'s training. An "Authorized Operators List" shou:d be posted near the control panel of the machine the operators are authorized to use. The machine custod:ar. shouid ensure operator familiarity with SoPs and al: machine safety reatures, and should make arrangements through the Health Physics representative for operators to attend the $H-1$ X-Ray Safety Training as soon as practicable rollowing assumption of their duties.

\section{Interlocks}

The machine custodian or operator should check a?l enclosure door safety interlocks on industrial $x$-ray equipment at least semi-annually for proper runctioning. Each test should be recorded on an interlock test-los wich should be posted on or near the control panel.

\section{Periodic Survey and Maintenance}

An initial radiation sur:ey is performed on all incidental $x$-ray devices over $40 \mathrm{kVp}$. Resurvey frequency is determined by $\mathrm{H}-1$ on a case-by-case basis.

Fo intentional devices, annual radiation protection surveys are performed by $\mathrm{H}-1$ on each machine and rollowing each time modifications to either the machine or measurement techniques affect the radiation pattern produced. The machine custodian should contact the Health Physics represetative prior to any repair,

Page 7 of 8 
maintanance, or nonroutine work which has the potentia?

of exposins any portiar a the body to the primary bean.

Persorine? Exposure Tuidelines

For information on maintaining personne? exposure as :ow as praatiaable and within occupational exposure limits, see Tachnical Bulletin 502, "Rajiation Protection

Standarts."

FORMS

HS\&E 5-3A. X-Ray Generating Device Registration

Page $B$ of 8 


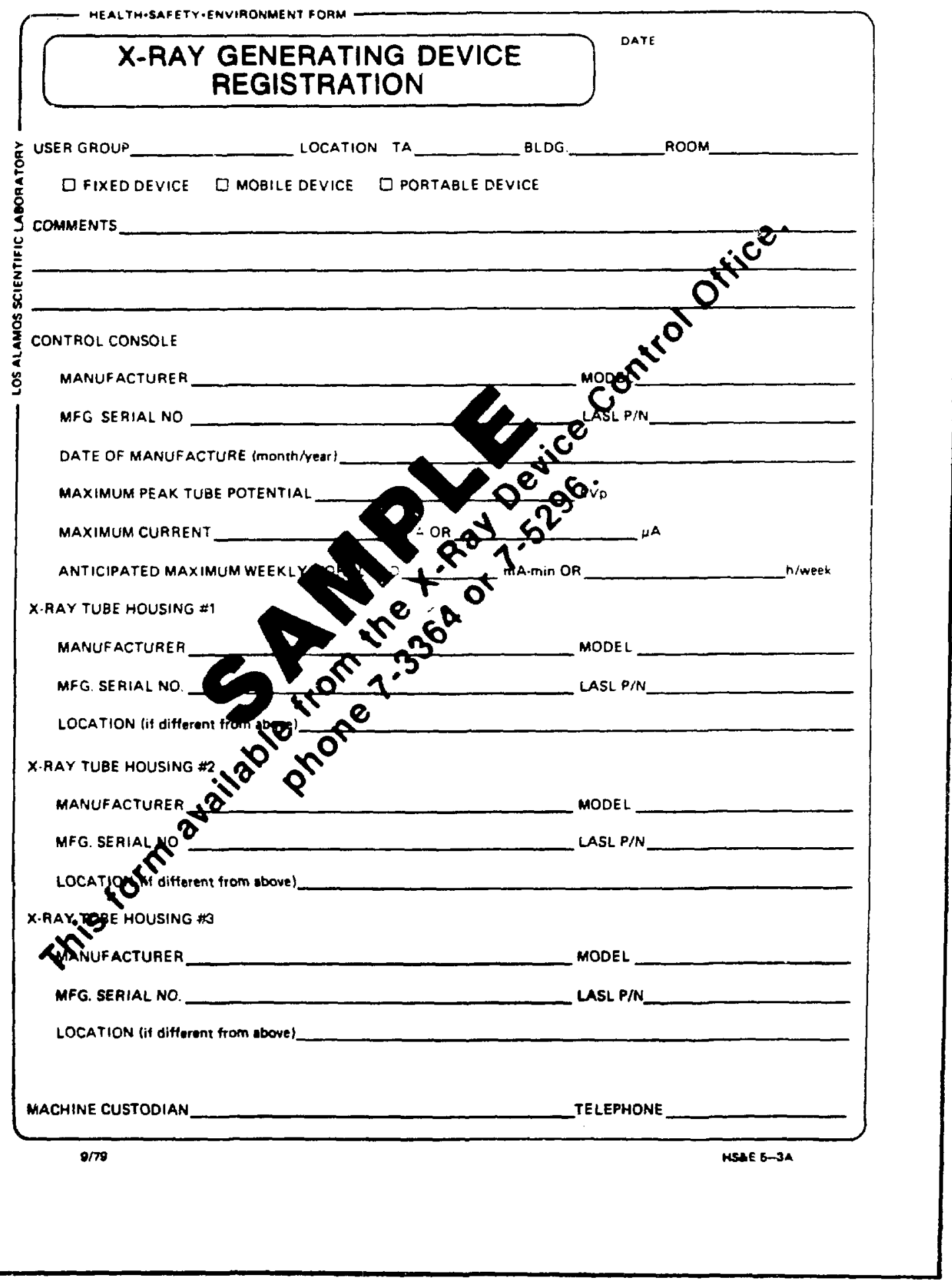




\section{TECHNICAL BULLETIN}

\section{ANALYTICAL X-RAY DEVICES}

\section{INTRODUCTION}

Inas bulletin supplements the Administrative Requirements for x-ray generating devices referenced below. It covers desigr, installation, and operating safety requirements for analytical $x$-ray devices, including $x$-ray diffraction and $x$-ray fluorescence analysis systems, and electron microscopes. It does not include electrical safety guidelines or other considerations outside or radiation safety.

The Laboratory requires that all $x$-ray generating devices be approved by the Health Physics Group $(\mathrm{H}-1)$. Analytical $x$-ray devices must meet the guidelines and safety provisions of this bulletin to obtain such approval and receive the LASL compliance label.

\section{REFERENCES}

Health, Safety and Environment Manual, "X-Ray Generating Devices," Administrative Requirements 5-3, Los Alamos Scientific Laboratory manual LA-7940-M.

ANSI N43.2, "Radiation Safety for X-Ray Diffraction and Fluorescence Analysis Equipment."

Electron Microscopy Society of America, "Handbook of X-Ray Safety for Electron Microscopists" (1973).

\section{CONTROL PANEL LABELIHG}

In addition to the LASL compliance label required to operate the equipment, control panels must also display the following two labels: 
- a clearly visible and legible label bearing the conventional radiation symbol and words that communicate "CA'JTION: THIS EQUIPNENT PRODUCES $X$ RAYS WHEN ENERGIZED"

- a label stating that $H-1$ should be notified wher. the unit is to be moved, transferred, or altered.

\section{ELECTRON MICROSCOPES}

Safety interlocks must be provijef on all electron microscope access panels which present a potential rafiation hazard.

The exposure rate during any phase of operation of an electron microscope at the maximum-rated continuous beam. current for the maximum rated accelerating potential mus: not exceed the rollowing levels at a distance of $5=m$ from any accessible external surface:

- $0.5 \mathrm{~m}$ /hr for microscopes with operating potentijls less than $200 k V p$.

- $2.5 \mathrm{mR} / \mathrm{hr}$ for microscopes with operating potentiazs greater than $200 \mathrm{kVP}$.

\section{X-RAY DIFFRACTION AND FLUORESCENCE ANALYSIS SYSTEMS}

\section{Common Provisions}

A fall-safe design should be incorporated in existing $x-$ ray diffraction and fluorescence analysis systems and must be designed into equipment purchased after the effective date of this bulletin. This Buideline will apply whenever fail-safe design is specified. The rail-safe design is one in which all failures of indicator or sarety components that can reasonably be anticipated cause the equipment to rail in a mode such that personnel are safe from exposure to radiation. For example, if a light indicating "X RAYS ON" rails, the production of $x$ rays is automatically prevented; or if a shutter status indicator falls, the shutter automaticalizy closes.

Any accessories to the equipment, e.g., a powderdiffraction camera, must include a beam stop or other barrier so that the exposure rate due to the transmitted primary beam does not exceed $0.5 \mathrm{mR} / \mathrm{hr}$ under normal operating conditions.

Page 2 of 4 
warning lights or inticators labeled with the words "Y. RAYS ON" (or others having similar meaning) must be installed near all switches which energize an $x-r a y$ tibe. A fail-sare light or indicator must be installed in a conspicusus location near the $x$-ray tube housing to indicate when the $x-r a y$ tube is on. These indicators are to be energized automatically, and only when high vo?tage is applied to the $x-r a y$ tube or the tube current flows.

\section{Common Sareguards}

No operation involving removal of tube housings or modirications to shutters, collimators, or beam stops should be performed without ascertaining that the tube is off and will remain off until safe conjitions have beer restored. The main power switch, rather than safety interlocks, should be used for routjne shutdows is preparation for repairs.

Whenever manufacturer's alignment procedures are available, all prescribed sareguards are to be followes. It is not advisable to modify manufacturer's recommended safety procedures, and any attempt to do so should have prior approval of the user's group leader. If an alignment proceture may result in increasing the exposure rate in any area, the operator should erect temporary barriers and warning signs as required and should keep the area under surveillance until normal operation has been restored. Safety glasses should be used during open beam alibnment procedures to protect the eyes from an accidental primary beam exposure.

\section{Open Beam Systems}

In adjition to the above, all shutters in an open beat system must be provided with a conspicuous "SHUTTER OPEN" indicator of fail-safe design.

A guard or interlock which prevents entry of any part of the body into the primary beam should be provided.

Each port of the $x$-ray tube housing must be provided with a beam shutter. Whenever an accessory setup is not permanent (i.e., subject to rrequent or periodic change), the shutter must be interlocked with every accessory apparatus coupling or collimator, such that the poric will only be open when the collimator or coupling is 111 place. Shuters at unused ports should be secured to prevent casual opening.

Page 3 of 4 
Exposure rates adjacent to the system must not exceed $z=$ mR/hr. Whenever necessary, use leat foll and/or portat:o shields to reduce scetter or other sezondary radiat:ar. $t$ ? this leve?.

Tube-housing leakage must not excest $0.5 \mathrm{mR} / \mathrm{hr}$ as measured with all shutters closed at $5 \mathrm{~cm}$ from the surface of the housing under normal operation.

\section{Enciosed Beam Systems}

The radiation leakage limit ror an enclosed boam sys"or at $5 \mathrm{~cm}$ from any outer sur rase of the chamber is 0. $m R / h r$ during normal operation.

The $x-r$ ay tube, sample, detector, and anglyzing crys: (if used) must be enclosed in a chamber or coucled chambers that cannot be entered by any part of the boty during normal operation. The samplo chamber door or other closure must be interlocked with the $x-r a y$ tube high-voltage supply or a shutter in the primary bear s: that no $x-r a y$ beam can enter the sample chamber while it is open. This interlock is to be of rail-sace Jesigr.

\section{Selection of Enclosed or Open Bear. System}

An enclosed beam system should be selected over an opor. beam system whenever reasible. Ar. open beam system wi: only be approved if an enclosed beam system is impractical due to such operational requirements as the followinB:

- a need for frequent changes of attachments and configuration

- a need for making adjustments with the $x$-ray beam enerbized

- motion of specimen and detector over wije angular limits

- examination or large or bulky samples.

\section{REFERRALS}

Health Physics Group orfice, H-1 (7-5296)

Health Physics $X-R a y$ Device Control Office, H-1 (7-3364) 


\section{TECHNICAL BULLETIN}

\section{INDUSTRIAL CABINET X-RAY SYSTEMS}

\section{INTRODUCTION}

This bulletin supplements the Administrative Requirements for $x$-ray generating devices referenced below. It discusses design, installation, and operating safety requirements for industrial cabinet $x$-ray systems. It does not include electrical safety guidelines or other considerations outside of radiation safety.

The Laboratory requires that all x-ray generating devices be approved by the Health physics Group $(H-1)$. Cabinet $x-r a y$ systems must meet the guidelines and safety provisions of this bulletin to obtain such approval and receive the LASL compliance label.

\section{REFERENCES}

Health, Safety and Environment Manual, "X-Ray Generating Devices," Administrative Requirements 5-3, Los Alamos Scientific Laboratory manual LA-7940-M.

"Regulations for the Administration and Enforcement of the Radiation Control for Health and Safety Act of 1958," DHEW publication (FDA)76-8035, Federal Performance Standard for cabinet $x$-ray systems, 21 CFR 1020.40.

DEFINIIION OF TERMS

Cabinet $x$-ray system is an $x-r a y$ system with the $x-r a y$ tube instalied in an enclosure (the cabinet) that, independently of existing architectural structures (except the floor on which it may be placed), is intended to contain the portion of material being irradiated, 


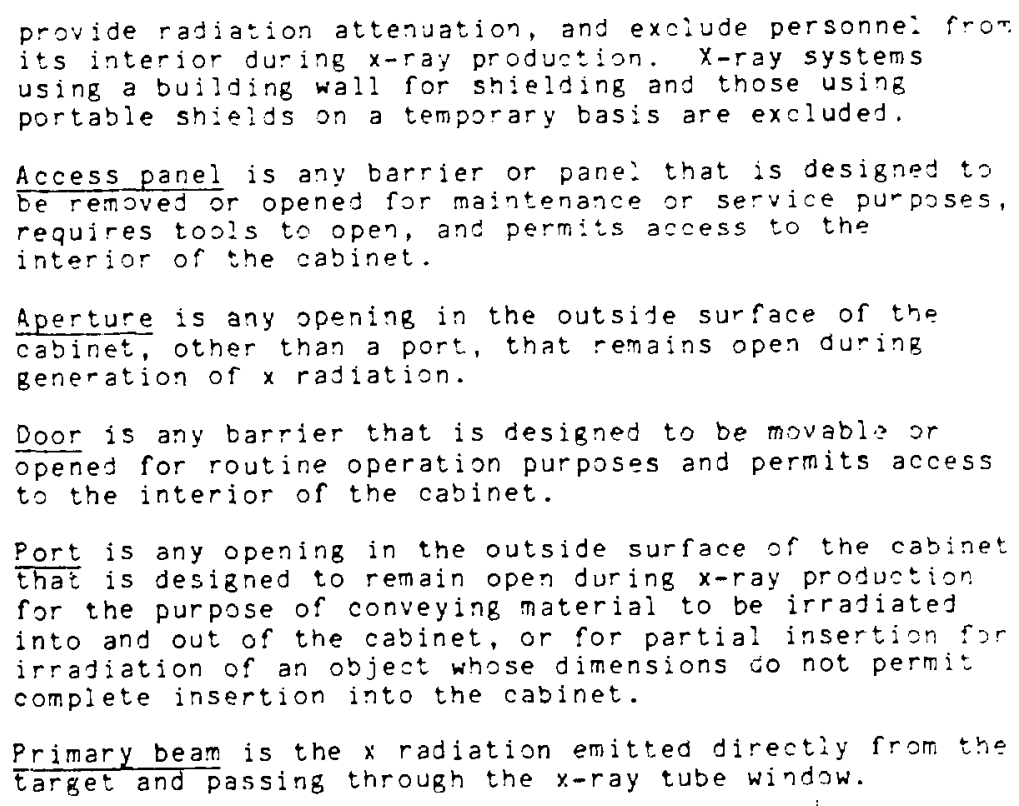

\section{PURCHASE OF NEW EQUIPMENT}

All equipment must be certified by the manufacturer as complying with the Federal Performazce Standard, 21 CFR 1020.40. Purchase requests should specify that the equipment must be certified as stated above.

\section{CONTROL PANEL LABELING}

In addition to the LASL compliance label required to operate the equipment, control panels must also display the following two labels:

- a clearly visible and legible label bearing the conventional radiation symbol and words that communicate "CAUTION: THIS EQUIPMENT PRODUCES $X$ RAYS WHEN ENERGIZED."

- a label stating that $\mathrm{H}_{-1}$ should be notified when the unit is to be moved, transferred, or altered.

Page 2 of 4 


\section{EMISSION LIMIT}

Radiation emitted from the cabinet must not exceed an exposure of $0.5 \mathrm{mR}$ in one hour at any puint $5 \mathrm{~cm}$ outsite the external surface. Measurements for compliance with this limit should be averaged over a cross-sectional area $0: 10 \mathrm{~cm}$.

\section{PORTS AND APERTURES}

The insertion of any part of the human body through any port into the primary beam must not be possible. The insertion of any part of the human body through any aperture must not be possible (this may be accomplished by the use $c^{-}$a baffle on the inside of the cabinet).

\section{SAFETY INTERLOCKS}

Each access panel must have at least one interlock. Each cabinet joor must have either a fail-safe interlock, a physical disconnect and an interlock, or two independent interlocks in series. The interlocks for cabinets designed to admit humans must not automaticaliy reset; that is, $x$-ray production should not be possible after opening and closing a door without the use of the "x-ray on" control to resume operation.

\section{CONTROLS AND INDICATORS}

A control or controls to initiate and terminate $x-r a y$ generation must be provided other than by the functioning of a safety interlock or the main power control.

A conspicuous warning light or indicator, labeled with the words "X RAYS ON" (or other words having similar meaning), must be installed near any switch that energizes an $x$-ray tube. The light or indicator is to be energized automatically and only when high voltage is applies to the $x-r a y$ tube or the tube current flows.

There must be at least one light or indicator, as described above, visible from each cabinet door and port.

\section{ADDITIONAL PROVISIONS FOR CABINETS DESIGNED TO ADMIT HUMANS}

The following must also be provided if the cabinet is of such a size or is so arranged that the operator cannot readily determine whether or not the cabinet is unoccupied:

Page 3 of 4 
- Audible and visible warning signals of the rotatine or flashing type within the cabinet that are actuated for at least 10 seconds immediately priar to the first initiation of $x$-ray generation after closing any door designed to admit humans. The visible warning signal must remain actuated during Irradiation. The audible signal is to be of a frequency or a sound pressure level such that it can be heard over background noise that may be present. Specifications for audible signals are recommended in ANSI N2.3(1957).

- A control within the cabinet for preventing and terminating $x$-ray generation (panic or scram switch) that cannot be reset, overridden, or bypassed from the outside of the cabine:.

- Signs inside the cabinet indicating the meaning of the warning siguals and panic switch.

- No means by which $x$-ray generation can be initiatez from within the cabinet.

- A procedure requiring a physical check of the cabinet by the operator before commencing or resuming operation.

\section{REFERRALS}

Health Physics Group orfice, $\mathrm{H}-1 \quad(7-5296)$

Health Physics $X-R a y$ Device Control office, $H-1$ (7-3354:

Page 4 of 4 


\section{TECHNICAL BULLETIN}

\section{INDUSTRIAL NONCABINET X-RAY INSTALLATIONS}

\section{INTRODUCTION}

This bulletin supplements the Administrative Requiremer:s for $x-r a y$ Benerating devices referenced below. It covers design, installation, and operating safety requiremen:s for industrial noncabinet $x-r a y$ installations. It does not include electrical safety guidelines or other considerations outside of radiation sarety.

Basically any installation which is so constructed and operated as to meet the ar,licable radiation protection. standards is acceptable. Huwever, if this were the on: requisite, the assumptions as to the use of the equipte:: and degree of occubancy might be subject to widely divergent interpretations. Therefore, to ensure certair. minimum standards of protection we find it advisable to classify installations: protective, enclosed, and open.

The Laboratory requires that all $x-$ ray generating devices be approved by the Health Physics Group (H-1). Industrial noncabinet $x-$ ray installations must meet the Buidelines and safety provisions of this bulletin to obtain such approval and receive the LASL compliance label.

\section{REFERENCES}

Health, Safety and Environment Manual, "X-Ray Generating Devices," Administrative Requirements 5-3, Los Alamos Scientific Laboratory manual LA-7940.

Health, Safety and Environment Manual, "Radiation Protection Standards," Technical Bulletin 502, Los Alamos Scientific Laboratory manual LA-7940-M. 
ANSI N543, "General Safety Standard for Installations Using Non-Medical $X-R a y$ and Sealed Gamma-Ray Sources, Enerbies up to to MeV."

ANSI N537, "Radiological Safety Standard for the Desizn of Rajiographic and Fluoroscopic Industrial X-Ray Equipment."

ANSI N2.3, "Immediate Evacuation Signal for Use in Industrial Installations where Radiation Exposure May occur."

\section{PURCHASE OF NEW EQUIPMENT}

All new equipment must meet all of the applicable design provisions of ANSI N537.

\section{LABELING}

A clearly visible and legible labei must be attached to the $x$-ray control panel bearing the conventional

radiation symbol and words that communicate "CAUTION:

THIS EQUIPMENT PRODUCES $X$ RAYS WHEN ENERGIZED."

The LASL compliance label must be attached to the $x$-ray tube housing.

A 1 abel must be attached to the $x$-ray tube housing stating that $H-1$ should be notified when the system is to be moved, transferred, or altered.

\section{CONTROLS AND INDICATORS}

a control or controls to initiate and terminate $x$-ray generation must he provided other than by the functioning of a safety lnterlock or the main power control.

A conspicuous warning light or indicator, labeled with the words "X RAYS ON" (or others having similar mearing) must be installed near any switch that energizes an $x-r a y$ tube. The $118 \mathrm{ht}$ or indicator is to be energized automatically and only when high voltage is applied to the $x$-ray tube or the tube current flows.

There must be at least one light or indlcator, as described above, visible from each exposure-room entrance door (does not apply for open installations).

Page 2 of 7 
PROTECTIVE AND ENCLOSED INSTALLATIONS

In addition to the labeling, control, and indicator requirements specified above, the following special provisions are required for all protective and enclosed installations.

\section{Enclosure}

The source and all objects exposed to the source must be within a permarient enclosure, within which no person is permitted to remair. during irradiation.

\section{Safety Interlocks}

Fail-sare interlocks must be provided to prevent access to the enclosure during irradiation. These interlocks should be of the type that do not automatically reset; i.e., if the operation of any $x-r a y$ tube has been interrupted by the opening of a door or panel to an installation, it should not be possible to resume operation by merely closing the door or panel in question. To resume operation, it should be necessary, in ajyition, to uso the X-RAYS ON control or a reset device on or near the control panel.

\section{Additional Provisions}

If the enclosure is of such a size or is so arranged that the operator cannot readily determine whether or not the enciosure is unoccupied, the following must be provided:

- Audit le and fail-safe visible warning signals of tne rutating or flashing type within the enclosure that are actuated a minimum of 20 seconds before irradiation can be started. The visible signal must remain actuated during irradiation. The audible signal is to be of a frequency or a sound pressure level such that it can be heard over background noise that may be present. Specifications for audible signals are recommended in ANSI N2.3(1967).

- A sign inside the exposure room that operates in conjunction with the warning signals described above and contains the radiation symbol and the words "DANGER: HIGH RADIATION AREA" or "CAUTION: HIGH RADIATION AREA."

Page 3 of 7 
- Suitable means of exit, so that any person who may be shut-in accidentally can leave the enclosure without delay.

- A control within the enclosure for preventing and/or terminating $x$-ray generation (panic or serar. switch) that cannot be reset, overridden, or bypassed from outside the room.

- Conspicuous signs inside the exposure room indicating the meaning of the warning signals and panic switch.

- No means by which $x-r a y$ generation can be initiated from within the enclosure.

- A procedure requiring a physical check of the enclosure by the operator before commencing or resuming operation.

\section{Emission Limits for Protective Installations}

For protective installations, the exposure at any accessible region $5 \mathrm{~cm}$ from the outside surface of the enclosure must not exceed $0.5 \mathrm{mR}$ in any one hour. This limit assures with reasonable probability that under practical conditions of occupancy and use, no person, either within the controlled area or in the environs of the installation, will be exposed to more than the maximum permissible dose limit. See Technical Bulletin 502, "Radiation Protection Standards," for applicable dose limits.

\section{Emission Limits for Enclosed Installations}

For enclosed installations, the exposure at any area accessible during irradiation $30 \mathrm{~cm}$ from the externa? surface of the enclosure must not exceed $10 \mathrm{mR}$ in any one hour. All accessible areas found to exceed this limit must be provided with either positive means to deny access to these areas during irradiation or additional shielding to reduce the exposure to below the specified limit. Positive means to deny personnel access incluje such things as fencing and locked or interlocked gates and doors. This exposure limitation must be met for any $x$-ray tube to be used in the enclosure and operating at any specifled tube current and potential rating within the manufacturer's published recommendations.

No beam-limiting device (collimator) or filters should be used during these tests unless they are permanently attached to the $x-r a y$ tube and the unit cannot be

Page 4 of 7 
operated without their use. The $x-r a y$ tube should be positioned and oriented so that the highest exposure rate will be encountered in the area under test provided that such positioning and orientation will serve a practical purpose in normal use and is not prohibited by the SOP.

No person, either within the controlled area or in the environs of the installation, is to be exposed to more than the maximum permissible dose limits (see Technical Bulletin 502). The accessible area in which exposure exceeds $5 \mathrm{mR}$ in any one hour must have signs posted showing the radiation symbol and the words "CAUTION: RADIATION AREA."

\section{OPEN INSTALLATIONS}

In addition to the labeling, control, and indicator requirements specified earlier, the following is required for open installations.

\section{Perimeter and Emission Requirements}

The $x$-ray tube and all objects exposed thereto must be within a conspicuously posted perimeter that limits the area in which the exposure can exceed $100 \mathrm{mR}$ in any one hour. The sign must display the radiation symbol and the WOTdS "DANGER: HIGH RADIATION AREA" or "CAUTION: HIGH RADIATION AREA." An effort should be made to limit the exposure at the perimeter to $2.5 \mathrm{mR}$ in one hour by use of portable shields whenever feasible.

No person may have access to the high radiation area within the perimeter nor remain in the area during irradiation. Positive means must be provided for preventing access, such as locked enclosure, during periods of unattended irradlation.

The perimeter of any area in which the radiation level is in excess of $5 \mathrm{mR}$ in any one hour must be defined and posted with a sign displaying the radiation symbol and the words "CAUTION: RADIATION AREA."

No person, either within a controlled area or in the environs of the installation, is to be exposed to more than the applicable maximum permissible dose ilmit (see Technical Bulletin 502).

When entering the installation after using $x$-rays, the operator should use a sultable survey meter andior chirper to verify that $x$-rays have been turned off.

Page 5 of 7 


\section{SELECTION OF INSTALLATION CLASS}

Fixed $x-r a y$ systems as well as mobile systems used routinely at one location must be designed to meet the requirements of either a protective or an enclosed installation. An open installation will only be approved in those situations where the use of one of the other classes is not feasible.

The classes differ in their relative dependence on inherent shielding, operating restriction, and supervision to secure the required degree of protection.

\section{Protective Installation}

This class provides the highest degree of inherent safety because the protection does not depend on compliance with any operating limitations. This type also has the advantage of not requiring restrictions in occupancy outside the enclosure since the built-in shielding is generally sufficient to meet the maximum permissible dose requirements for noncontrolled areas.

However, the low allowable exposure level $(0.5 \mathrm{mR} / \mathrm{hr})$ for this class of installation necessitates a higher degree of inherent shielding. For radiation sources of lower energies, and for smaller enclosures, the initial extra cost of the increased shielding is usually insibnificart compared with the operational advantages.

At higher energies, as in the megavolt region with high workloads, the required additional shielding will usually make the use of this class extremely expensive compared with the enclosed installation.

\section{Enclosed Installation}

The shielding requirements for this class are considerably lower than for the Protective Installation. Restrictions in occupancy and workloads are relied upon in order to meet the maximum permissible dose limits. With proper supervision, this class offers a degree of protection similar to the protective installation.

\section{Open Installation}

This class should be selected only if operational requirements prevent the use of one of the other classes. Its use should be 1 im ited mainly to mobile and portable equipment where fixed shielding cannot be used.

Page 6 of 7 
The protection of personnel and the public depends almost entirely on strict adherence to safe operating proce-

dures. Only with this adherence can these installations provide a degree of protection similar to the other classes.

\section{REFERRALS}

Health Physics Group office, H-1 (7-5296)

Health Physics X-Ray Device Control office, $\mathrm{H}-1(7-3354)$

Page 7 of 7 